Article

\title{
A Density Functional Theory Study of the Adsorption of Benzene on Hematite $\left(\alpha-\mathrm{Fe}_{2} \mathrm{O}_{3}\right)$ Surfaces
}

\author{
Nelson Y. Dzade *, Alberto Roldan and Nora H. de Leeuw \\ Department of Chemistry, University College London, London WC1H 0AJ, UK; \\ E-Mails: alberto.roldan@ucl.ac.uk (A.R.);n.h.deleeuw@ucl.ac.uk (N.H.dL.) \\ * Author to whom correspondence should be addressed; E-Mail: nelson.dzade.10@ucl.ac.uk; \\ Tel.: +44-20-7679-1015; Fax: +44-20-7679-7463.
}

Received: 13 December 2013; in revised form: 20 January 2014 / Accepted: 31 January 2014 / Published: 14 February 2014

\begin{abstract}
The reactivity of mineral surfaces in the fundamental processes of adsorption, dissolution or growth, and electron transfer is directly tied to their atomic structure. However, unraveling the relationship between the atomic surface structure and other physical and chemical properties of complex metal oxides is challenging due to the mixed ionic and covalent bonding that can occur in these minerals. Nonetheless, with the rapid increase in computer processing speed and memory, computer simulations using different theoretical techniques can now probe the nature of matter at both the atomic and sub-atomic levels and are rapidly becoming an effective and quantitatively accurate method for successfully predicting structures, properties and processes occurring at mineral surfaces. In this study, we have used Density Functional Theory calculations to study the adsorption of benzene on hematite $\left(\alpha-\mathrm{Fe}_{2} \mathrm{O}_{3}\right)$ surfaces. The strong electron correlation effects of the $\mathrm{Fe} 3 d$-electrons in $\alpha-\mathrm{Fe}_{2} \mathrm{O}_{3}$ were described by a Hubbard-type on-site Coulomb repulsion (the DFT $+\mathrm{U}$ approach), which was found to provide an accurate description of the electronic and magnetic properties of hematite. For the adsorption of benzene on the hematite surfaces, we show that the adsorption geometries parallel to the surface are energetically more stable than the vertical ones. The benzene molecule interacts with the hematite surfaces through $\pi$-bonding in the parallel adsorption geometries and through weak hydrogen bonds in the vertical geometries. Van der Waals interactions are found to play a significant role in stabilizing the absorbed benzene molecule. Analyses of the electronic structures reveal that upon benzene adsorption, the conduction band edge of the surface atoms is shifted towards the valence bands, thereby considerably reducing the band gap and the magnetic moments of the surface Fe atoms.
\end{abstract}


Keywords: hematite $\left(\alpha-\mathrm{Fe}_{2} \mathrm{O}_{3}\right)$; surfaces; benzene; adsorption and density functional theory

\section{Introduction}

Iron oxides constitute one of the largest mineral groups on Earth and are composed of principally iron and oxygen and/or hydroxide. They are ubiquitous in nature and are present in soils and rocks, in lakes and rivers, on the seafloor, and in organisms [1]. To date, sixteen different types of iron oxides are known which differ in composition, oxidation state of $\mathrm{Fe}$ and, most importantly, in crystal structure $[1,2]$. The diversity in chemical structure and physical properties of the iron oxide phases provide many different applications at the research and industrial levels (see Figure 1). Iron oxides have been investigated for their potential use in a wide range of important applications, such as catalysis, electrochemistry, magnetization, biomedical science, as pigments in ceramic glazes, and in environmental applications [3-8]. Hematite, maghemite, and magnetite, for example, are used as catalysts in the Fischer-Tropsch synthesis of hydrocarbons and ammonia [9-14], and in the synthesis of styrene through the dehydrogenation of ethylbenzene [15-17]. Iron oxides are also important as pigments, where natural and synthetic pigments are used in the manufacture of red, brown, and black paints or as admixtures, for example in colored glasses [18-20]. Other industrial applications of iron oxides are in magnetic devices [21,22], or semiconductors [23], when the iron oxide can be incorporated into the interlayer of layered compounds as semiconductor pillars which show excellent photocatalytic activity. In medical applications, nanoparticulate magnetic and super-paramagnetic iron oxides have been used for drug delivery in the treatment of cancer [24,25].

Figure 1. Scheme of the different scientific disciplines concerned with iron oxides. Reproduced with permission from reference [2]. Copyright 2003 John Wiley and Sons.

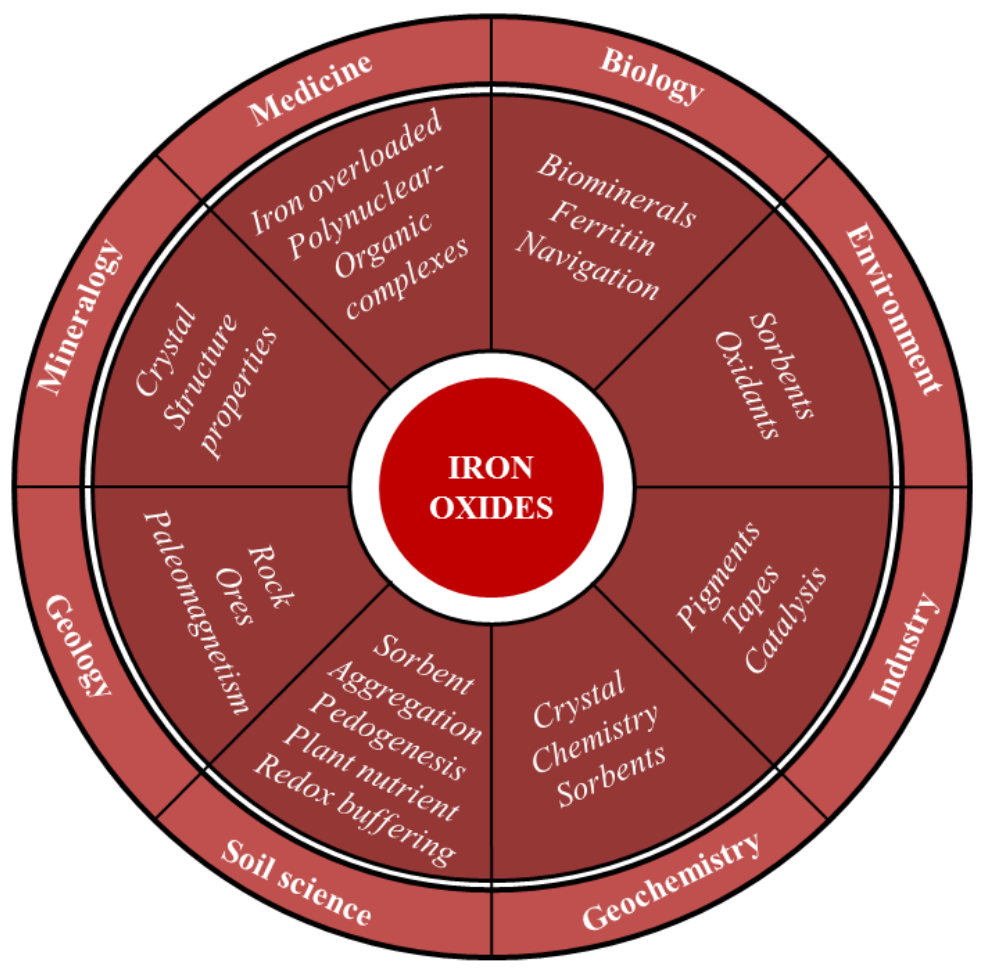


There has also been considerable interest in using iron oxides and hydroxides to remove environmental pollutants from underground water and soil sediments due to their characteristically high surface areas, higher adsorption affinity and capacity, and faster adsorption rate in comparison to many other adsorbents [26-29].

The adsorption of organic and inorganic pollutants on mineral surfaces is an important process in environmental chemistry as the adsorption processes influence the transport and activity of contaminants in soils, sediments, and water, and therefore affect the bioavailability, biodegradability, and fate of harmful organic wastes [30-32]. To understand and influence these processes it is desirable to obtain a detailed insight into the individual interactions at the molecular level. Although many experiments have been devoted to sorption of inorganic oxyanions (chemical compounds with the generic formula $\mathrm{A}_{x} \mathrm{O}_{y}{ }^{{ }^{-}}$: e.g., phosphate $\left(\mathrm{PO}_{4}{ }^{3-}\right.$ ) [33-44] and organic compounds (including organic acids, amines, sugars, fatty acids, phenols, alkanes, and a range of aromatic compounds) [2,45-52] on iron (hydr)oxides, the detailed mechanism of sorption is not completely clear. The diverse interactions and reactions occurring at the surface or in the interlayer space of iron oxide minerals creates a complex situation that is difficult to interpret. In this situation, computer simulation methods become a very useful tool to study surface complexes at the molecular level to provide detailed insight into the surface and electronic structures and adsorption processes.

During the last two decades, an increasing number of theoretical investigations have been performed to describe the bulk and surface properties of iron (hydr)oxides. The interactions of various molecular species with iron (hydr)oxide surfaces have also been extensively investigated. The magnetic and electronic structure of $\alpha-\mathrm{Fe}_{2} \mathrm{O}_{3}$ has been studied via the Density Functional Theory methods [53-57], whereas similar calculations of point defects (e.g., interstitials, vacancies and substitutional dopants) in hematite have shown these to have profound effects on the electronic properties [57-60]. Trainor et al. [61] and Wang et al. [62] have computed various possible structures of the hematite (0001) surface using spin-density functional theory, whereas, de Leeuw and Cooper have employed classical interatomic potential calculations to simulate the hydrated surface structures of white rust $\left[\mathrm{Fe}(\mathrm{OH})_{2}\right]$, goethite $(\mathrm{FeOOH})$ and hematite $\left(\alpha-\mathrm{Fe}_{2} \mathrm{O}_{3}\right)$ [63]. The structure of the $\{0001\}$ and $\{0112\}$ surfaces of hematite and their interaction with water have also been reported by other theoretical groups [64-72]. Some of these calculations have shown that adsorbed water molecules dissociate heterolytically on the $\left(\begin{array}{l}1 \times 1 \\ \times\end{array}\right)-\alpha-\mathrm{Fe}_{2} \mathrm{O}_{3}\left(\begin{array}{lll}0 & 1 & 1\end{array}\right)$ surface and that the presence of surface hydroxyls results in large interlayer relaxations [64]. Rustad et al. [73] and Shroll et al. [74] have used classical interatomic potential calculations and molecular dynamics simulations to investigate the goethite-water interface, whereas the surface energies of the different surface terminations of goethite were investigated by Rakovan et al. at ab initio level, applying periodic boundary conditions [75].

Computer simulations have also been used successfully to investigate the interactions and properties of oxyanions on iron (hydr)oxides surfaces, predicting the stable adsorption complexes and the mechanisms of sorption [76-87]. Spectroscopic studies [34-44] and pressure-jump relaxation kinetics measurements $[84,85]$ have shown that arsenate and phosphate adsorb on iron (hydr)oxide through the formation of inner-sphere surface complexes. However, the nature of the inner-sphere complex has been controversial as none of these studies had the ability to determine directly the registry of the adsorbed phosphate and arsenate on iron (hydr)oxides surfaces. In an attempt to resolve the controversy over the inner-sphere surface complexation mechanism, Sherman et al. performed 
density functional theory (DFT) calculations to predict the geometries and relative energies of $\mathrm{AsO}_{4}-\mathrm{FeOOH}$ surface complexes and found the bidentate corner-sharing complex to be substantially more favored energetically (by $55 \mathrm{~kJ} / \mathrm{mol}$ ) over the hypothetical edge-sharing bidentate complex [76]. The bidentate corner-sharing complex was recently predicted with DFT calculations for arsenate on hematite surface [77], whereas quantum mechanical calculations were also applied to resolve the controversies about sulphate surface complexes on iron hydroxides [79,83]. Similarly, the adsorption structures of $\mathrm{Cr}(\mathrm{VI})$ [78], $\mathrm{Se}(\mathrm{IV})$ [86], and $\mathrm{Sb}(\mathrm{III})$ and $\mathrm{Sb}(\mathrm{V})$ [87] species on hematite surfaces have also been studied using DFT methods within periodic slab models.

There also exists a large literature on sorption studies conducted with natural minerals and other geosorbents, like sediments or soils, with varying organic matter content [88-101]. For example, the interaction between the (110) goethite surface and acetic acid, acetate, 2,4-dichlorophenoxyacetic acid, 2,4-dichlorophenoxyacetate and benzene have been studied by means of quantum mechanical calculations using the B3LYP approach [88], whereas the interaction of esters and acids with iron oxide surfaces has also been reported [47,89]. Molecular dynamics simulations have been used to study the adsorption processes associated with the deposition of $n$-alkanes (e.g., wax) on hematite surfaces [91-93]. The sorption of hydrophobic organic contaminants (HOC), including benzene and polycyclic aromatic hydrocarbons (PAHs), from aqueous solutions to the surface iron oxide mineral phases has been intensively investigated over the past three decades [102-106]. Several competing mechanisms are proposed to explain the sorption of PAHs to the mineral surfaces. For non-polar hydrophobic species like PAHs, a charge-induced dipole-dipole interaction between the positively charged sorption domain and the electron-rich $\pi$-system of the aromatic ring has been suggested [107]. Another suggestion based on cation- $\pi$ interactions between the $\pi$-electrons of aromatic rings and cations was recently identified in a wide range of natural systems, including the sorption of the mono-aromatic ring of benzene and benzene substitutes to specific soil organic matter domains or to mineral surfaces [108-110]. However, despite these proposed explanations, evidence of the detailed nature of the interactions of PAHs with mineral surfaces at a molecular level are still limited. It was only recently that the interaction of benzene with the mineral goethite was studied by means of quantum mechanical calculations based on density functional theory [88]. Similarly, a systematic DFT study of the interactions between a set of mono- and polycyclic aromatic hydrocarbons and the (110) goethite surface have shown that these species form relatively weak surface complexes having their molecular plane parallel to the surface plane [29]. The source of the mineral-adsorbate interactions was attributed to the polarization of the $\pi$-system by polar $\mathrm{OH}$ groups and to the formation of weak hydrogen-bonds where the $\pi$-system acts as a proton acceptor.

Despite the significant interest in understanding the interactions of organic compounds with iron oxide surfaces, the sorption mechanism of aromatic compounds on hematite surfaces is still not clear. In this paper we present the results of the molecular adsorption of benzene on the (0001) and (0112) surfaces of hematite under vacuum conditions using Density Functional Theory techniques. Insight into the nature of binding of benzene at the hematite surfaces is discussed and the effect of the adsorbed benzene molecule on the electronic and magnetic properties of hematite surfaces before and after adsorption is analyzed. Our calculations show that the chemisorbed benzene molecule decreases the magnetic moment of the interacting surface Fe atoms. 


\section{Computational Methods}

Geometry optimizations were carried out using the Vienna Ab-initio Simulation Package (VASP) code [111-114], which employs a basis set of plane-waves to solve the Kohn-Sham equations of the density functional theory in a periodic system. All calculations were spin-polarized and the exchange-correlation energy was calculated within the generalised gradient approximation (GGA) using the form of the functional proposed by Perdew and Wang (PW91) [115,116]. To correct for the strong electronic correlation of the Fe $3 d$-electrons, the GGA+U method $(\mathrm{U}=5.0 \mathrm{eV})$ is applied in the form proposed by Liechtenstein and Dudarev et al. [117,118]. The reader is referred to Reference [119] for the implementation within VASP and a more detailed description of the GGA+U method. Dispersion forces were accounted for in our calculations using the DFT-D2 method of Grimme [120], which accurately describes the interaction between organic molecules and solid surfaces $[121,122]$. The Brillouin zone was sampled using $11 \times 11 \times 7$ and $5 \times 5 \times 1$ Monkhorst-Pack [123] mesh $k$-points for bulk and surface calculations, respectively. For the final single-point runs for the calculation of the electronic and magnetic properties, a mesh of $7 \times 7 \times 1 k$-points were employed. Such dense grids and a truncation kinetic energy of $400 \mathrm{eV}$ for the plane waves ensured an accurate description of properties that are influenced by sharp features in the density of states.

The structure of bulk hematite was modeled by a hexagonal cell consisting of six formula units and the different surface structures were modeled with $(2 \times 2)$ supercells ensuring that the minimum distance between the benzene molecule and its images in the neighboring cells is $\sim 5 \AA$. A vacuum region of $15 \AA$ was tested to be sufficient to avoid interaction between slabs. The atoms of the adsorbate and the four topmost layers of the slab were allowed to relax unconstrained until residual forces on all atoms reached $0.01 \mathrm{eV} / \AA$. We did not include symmetry constraints in the structural optimization; in particular, the adsorbate was free to move away laterally and vertically from the initial site or reorient itself to find the minimum energy adsorption structure. For the isolated benzene molecule we used a cell with lattice constants of $15 \AA$, sampling only the $\Gamma$-point of the Brillouin zone.

\section{Results and Discussion}

\subsection{Bulk $\alpha-\mathrm{Fe}_{2} \mathrm{O}_{3}$ Structure}

Among the iron oxides, corundum-type $\alpha-\mathrm{Fe}_{2} \mathrm{O}_{3}$ (hematite) is the most thermodynamically stable form of iron oxide under ambient conditions and as such, it is also the most common form of crystalline iron oxide [1]. Hematite is isostructural with corundum $\left(\alpha-\mathrm{Al}_{2} \mathrm{O}_{3}\right)$ and cromia $\left(\alpha-\mathrm{Cr}_{2} \mathrm{O}_{3}\right)$, which have been studied extensively, both by means of atomistic simulation techniques and experimentally [53-57,63,124-126]. The hematite structure contains iron and oxygen atoms arranged in a trigonal-hexagonal scalenohedral (class) structure with space group R-3c and lattice parameters

$a=b=5.0356 \AA, c=13.7489 \AA$, with six formula units per unit cell [1]. The trigonal-hexagonal and the primitive rhombohedral cells are shown in Figure 2. 
Figure 2. Schematic illustration of the (a) hexagonal unit cell and (c) the rhombohedral primitive cell of $\alpha-\mathrm{Fe}_{2} \mathrm{O}_{3}$. The face-sharing octahedra in (a) and (c) are shown in (b) and (d) respectively. Color scheme: $\mathrm{Fe}=$ grey and $\mathrm{O}=$ red.

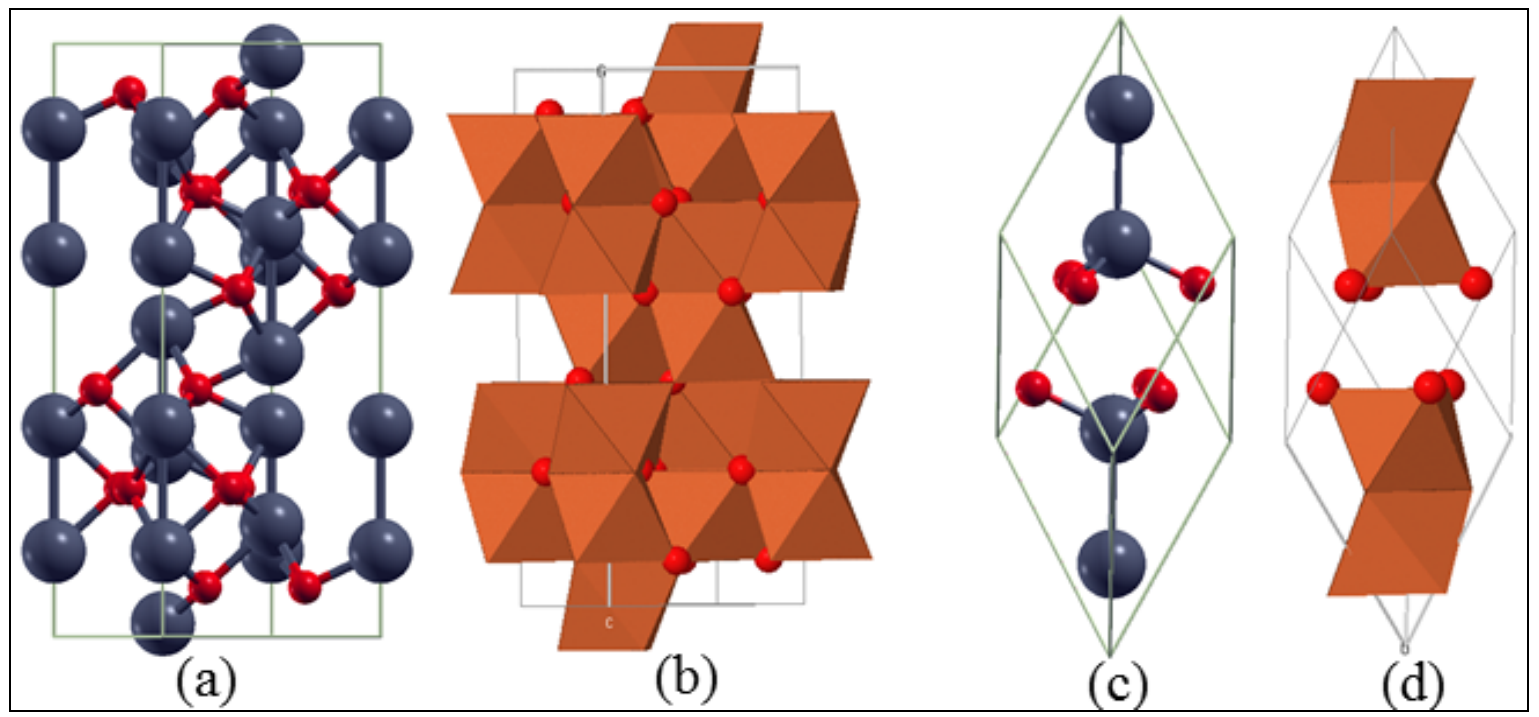

It is easy to understand the hematite structure based on the packing of the anions, $\mathrm{O}^{2-}$, which are arranged in a hexagonal closed-packed lattice along the [001] direction with the cations $\left(\mathrm{Fe}^{3+}\right)$ occupying two-thirds of the octahedral interstices in the hexagonal unit. The arrangement of the cations produces pairs of $\mathrm{FeO}_{6}$ octahedra that share edges with three neighboring octahedra in the same plane and one face with an octahedron in an adjacent plane in the [001] direction (see Figure 2b).

The arrangement of the oxygen anions and the high-spin $\left(d^{5}\right)$ iron cations naturally affects the orientation of the iron atoms' spin magnetic moment and thus the observed bulk magnetic properties of hematite. In this study, we have probed different magnetic configurations and have found that the lowest energy corresponds to the antiferromagnetic structure, in agreement with experimental observations [2]. The anti-ferromagnetic (AFM) structure is shown in Figure 3 where iron atoms are coupled ferromagnetically within a single octahedral layer, and alternating layers are coupled anti-parallel along the [0001] direction [127,128]. However, as all iron atoms have an equivalent octahedral environment, the electronic and magnetic properties will be the same at each iron site.

Given the fact that the $\mathrm{Fe} 3 d$-electrons in $\alpha-\mathrm{Fe}_{2} \mathrm{O}_{3}$ are strongly correlated, methods beyond standard density functional theory (DFT) are needed to correctly describe the system in terms of electronic and magnetic properties. Earlier standard DFT studies of bulk $\alpha-\mathrm{Fe}_{2} \mathrm{O}_{3}$ have shown that these correlation effects cannot be treated appropriately within the local-spin density approximation (LSDA), even with the spin-polarized generalized-gradient approximation (SGGA) [55,129,130]. These standard DFT calculations predicted band gaps that were too small or non-existent, magnetic moments too small, and also incorrect positions of the iron $3 d$-orbitals in relation to the oxygen $2 p$ states, characterizing the $\alpha-\mathrm{Fe}_{2} \mathrm{O}_{3}$ as a $d$ - $d$ Mott-Hubbard insulator, whereas the spectroscopic evidence argues in favor of a charge-transfer insulator [131-133]. 
Figure 3. Hexagonal $\alpha-\mathrm{Fe}_{2} \mathrm{O}_{3}$ lattice with anti-ferromagnetic spin arrangements indicated by up (yellow) and down (white) arrows at the Fe sites. Color scheme: $\mathrm{Fe}=$ grey and $\mathrm{O}=$ red.

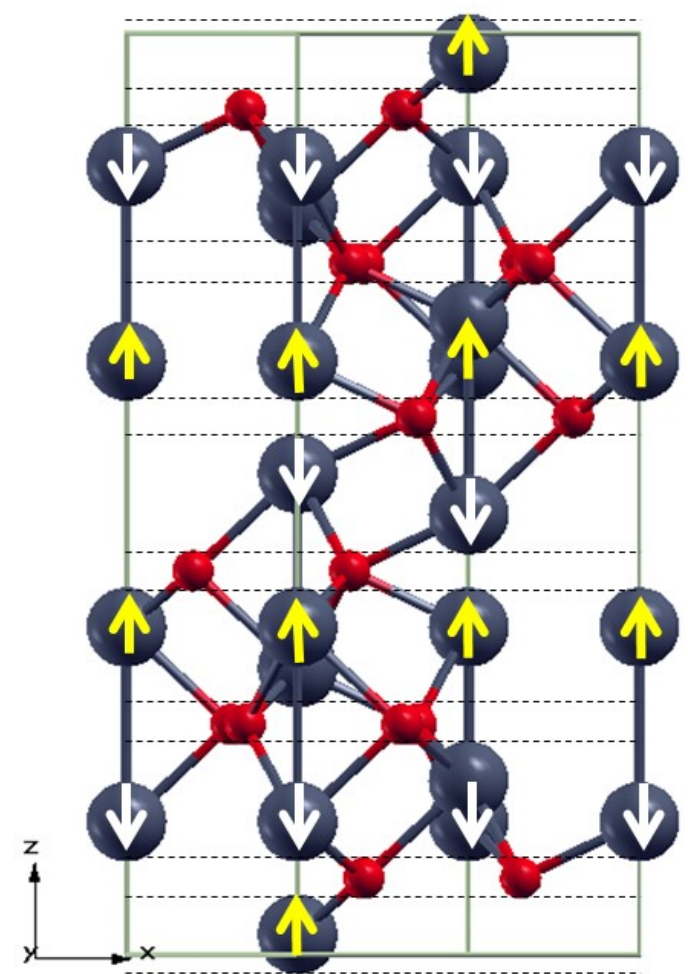

In this study, the strong intra-atomic electronic correlations were accounted for by adopting the DFT-GGA+U approach, which adds an on-site Coulomb repulsion to the DFT Hamiltonian. We have tested different $\mathrm{U}$-values and their implications for the electronic band-gap and Fe magnetic moment and found that $U=5.0 \mathrm{eV}$ provides a good description of the band-gap (2.1 eV) and the Fe magnetic moment $\left(4.23 \mu_{\beta}\right)$, which compares well with the experimental band-gap (1.9-2.2 eV) [134] and Fe magnetic moment $\left(4.6-4.9 \mu_{\beta}\right)[135,136]$. The calculated lattice parameters $a=b=5.024 \AA$ and $c=13.658 \AA$ are also in good agreement with experiment [1]. Rohrbach et al. [54] and Bandyopadhyay et al. [56] have also shown that the DFT $+\mathrm{U}$ method (U-value $=5 \mathrm{eV}$ ) provides a good description of the band-gap and magnetic moment of $\mathrm{Fe}$ in hematite and chromia $\left(\mathrm{Cr}_{2} \mathrm{O}_{3}\right)$ and our calculated gap width and Fe magnetic moments compares very well with the results of other recent theoretical calculations [137,138]. In Figure 4, we show how the electronic band-gap increases with increasing strength of the on-site Coulomb repulsion, where $U=5 \mathrm{eV}$ predicts the gap width $(2.1 \mathrm{eV})$, which falls within the experimental range (shaded area). It is also evident from the density of states plotted at $U=5 \mathrm{eV}$ (see Figure 5) that the occupied states near the Fermi level are mainly composed of the O $2 p$ states with a small contribution of the Fe $3 d$ states, in agreement with experimental measurements that show that hematite has the valence band edge dominated by the $\mathrm{O} 2 p$ states [131-133]. The conduction band is dominated by Fe $3 d$ states, suggesting that $\alpha-\mathrm{Fe}_{2} \mathrm{O}_{3}$ is an $\mathrm{O} 2 p \rightarrow \mathrm{Fe} 3 d$ charge transfer insulator in agreement with the experimental evidence. 
Figure 4. Electronic band-gap for $\alpha-\mathrm{Fe}_{2} \mathrm{O}_{3}$ plotted against different U-values. The experimental band-gap range is indicated by the shaded area.

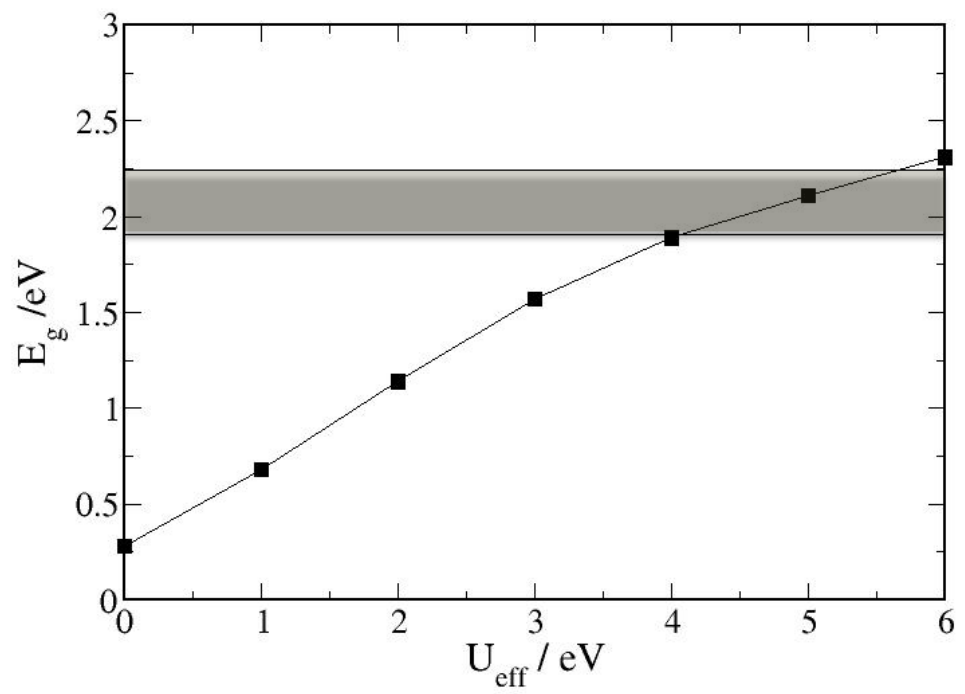

Figure 5. Density of states (DOS) of $\alpha-\mathrm{Fe}_{2} \mathrm{O}_{3}$ with $\mathrm{GGA}+\mathrm{U}=5 \mathrm{eV}$. The Fermi level is set to zero as shown by the dashed line.

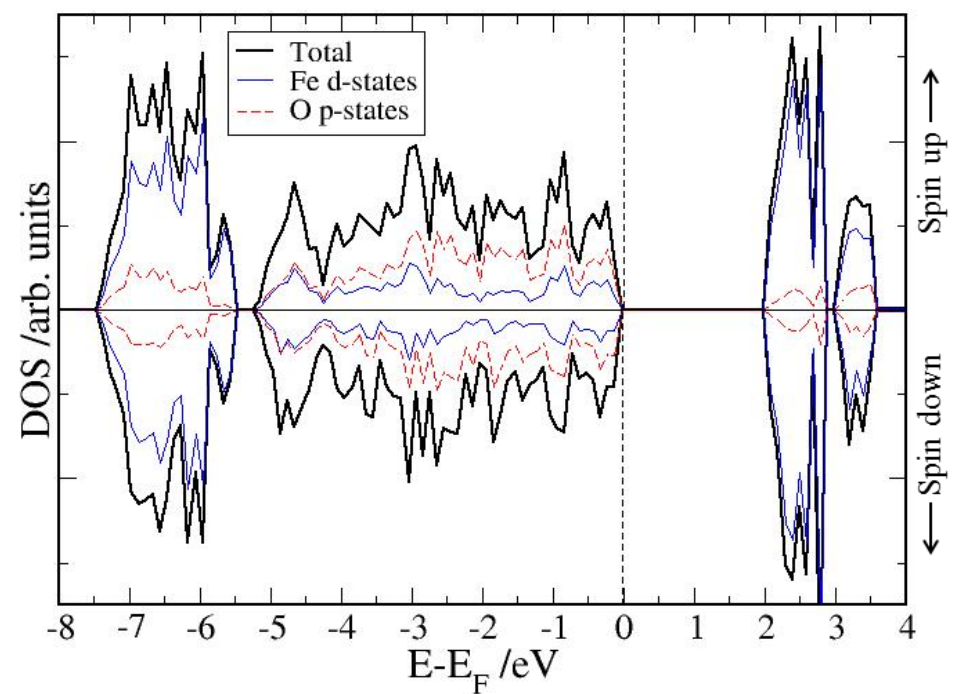

\subsection{The Structure of $\alpha-\mathrm{Fe}_{2} \mathrm{O}_{3}$ Surfaces}

Unravelling the relationship between the atomic surface structure and other physical and chemical properties of metal oxides is challenging due to the mixed ionic and covalent bonding often found in metal oxide systems [139]. Theoretical calculations have, however, proven to be an indispensable complementary tool to experiments in elucidating our understanding of the surface structures of metal oxides and they have been used extensively to study the structure of the clean and hydrated hematite surfaces in the literature [63-72].

The $\{0001\}$ and $\{0112\}$ surfaces of natural hematite have been shown to be the dominant growth faces [2] and these planes are therefore the ones studied in this work as well. Earlier investigations of the (0001) surface of both bulk $\alpha-\mathrm{Fe}_{2} \mathrm{O}_{3}$ and epitaxial thin films, using qualitative low energy electron diffraction (LEED) [140-144] and scanning tunneling microscope (STM) [145-150], have shown 
significant variations in the nature of the surface ordering depending on the method of surface preparation. Detailed structural characterization of the $\{0001\}$ surface under ultrahigh vacuum and clean conditions revealed that both $\mathrm{Fe}$ - and O-terminations coexist under different conditions of temperature and oxygen partial pressure [149-152]. Theoretical calculations by Trainor et al. [61] and Wang et al. [62] showed that the $\{0001\}$ surface can be terminated by either a single or double Fe layer or by oxygen ions, although the unreconstructed double Fe-termination and oxygen-terminated surface are dipolar. We have, therefore, considered only the non-polar single Fe-termination in this study where the top and side views are schematically shown in Figure 6.

We have found that the single-iron terminated $\{0001\}$ surface shows strong relaxations of the surface layers and interlayer spacings, a characteristic of most metal oxide surfaces. The surface energy of the single-iron terminated $\{0001\}$ is calculated to be $1.66 \mathrm{~J} \mathrm{~m}^{-2}$ similar to the results of de Leeuw et at. [63], Mackrodt et al. [153], and Reeves and Mann [154]. In Table 1, we summarize the optimized interlayer spacings compared with previous theoretically predicted values and experimentally observed interlayer spacings (Thevuthasan et al.) using X-ray photoelectron diffraction [151]. Generally, our calculated inward relaxations of the layer spacings of the single-Fe terminated $\alpha-\mathrm{Fe}_{2} \mathrm{O}_{3}(0001)$ surface are consistent with the X-ray photoelectron diffraction results and with earlier theoretical calculations $[62,65]$ but the magnitude of the relaxation differs.

Figure 6. Schematic representation of the side and top views of the single Fe-terminated $\alpha-\mathrm{Fe}_{2} \mathrm{O}_{3}(0001)-p(2 \times 2)$ surface structures. The terminating $\mathrm{Fe}$ atoms are highlighted in yellow circles in the top view. Color scheme: iron $=$ grey and $\mathrm{O}=$ red.
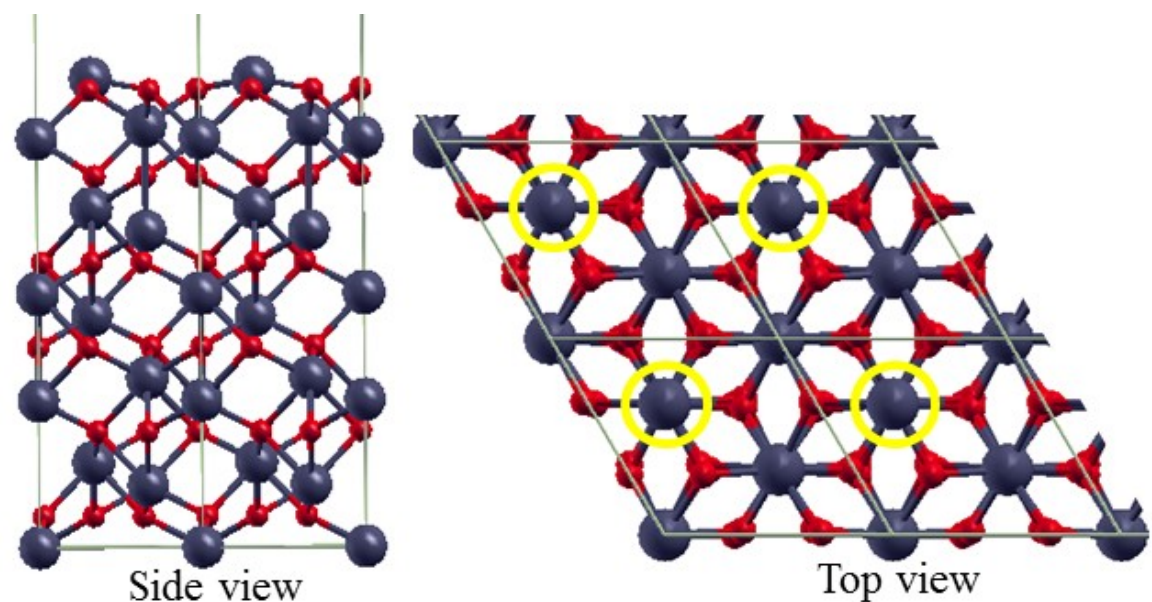

Top view

Table 1. Optimized interlayer spacing $(\AA)$ and percent relaxations for the single-iron terminated $\alpha-\mathrm{Fe}_{2} \mathrm{O}_{3}(0001)$ surfaces.

\begin{tabular}{ccccc}
\hline Investigations & $\begin{array}{c}\text { L1-L2 } \\
\text { (bulk }=\mathbf{0 . 8 5})\end{array}$ & $\begin{array}{c}\text { L2-L3 } \\
\text { (bulk }=\mathbf{0 . 8 5 )}\end{array}$ & $\begin{array}{c}\text { L3-L4 } \\
\text { (bulk }=\mathbf{0 . 6 1})\end{array}$ & $\begin{array}{c}\text { L4-L5 } \\
\text { (bulk }=\mathbf{0 . 8 5})\end{array}$ \\
\hline Theory (This work) & $0.40(-52 \%)$ & $0.91(+8 \%)$ & $0.45(-26 \%)$ & $1.05(+23 \%)$ \\
Theory (Wang et al. $[62])$ & $0.36(-57 \%)$ & $0.90(+7 \%)$ & $0.46(-23 \%)$ & $0.97(+15 \%)$ \\
Theory (Wasserman et al. [65]) & $0.43(-49 \%)$ & $0.82(-3 \%)$ & $0.36(-40 \%)$ & $1.02(+21 \%)$ \\
Theory (de Leeuw et al. $[63])$ & $0.21(-76 \%)$ & $0.90(+7 \%)$ & $0.42(-31 \%)$ & $0.97(+15 \%)$ \\
XPD (X-ray photoelectron diffraction) & $0.50(-41 \%)$ & $1.0(+18 \%)$ & $0.55(-9 \%)$ & $1.24(+47 \%)$ \\
$\quad$ (Thevuthasan et al. $[151])$ & & & &
\end{tabular}


The antiferromagnetic ordering of the bulk hematite is retained at the (0001) surface. We have however found that the magnetic moments of the surface layer Fe atoms are slightly reduced $\left(3.97 \mu_{\beta}\right)$ compared with that of the bulk oxide Fe atoms $\left(4.23 \mu_{\beta}\right)$. The change in the coordination of the surface atoms compared to those in the bulk modifies the shape of the bands of the $\mathrm{O} 2 p$ and Fe $3 d$ hybridization, which consequently affect the local magnetic moments. The electronic density of states for the relaxed single Fe-terminated $\alpha-\mathrm{Fe}_{2} \mathrm{O}_{3}(0001)$ surface, shown in Figure 7, reveals that the surface remains semi-conducting but with a reduced gap width $(\sim 1.7 \mathrm{eV})$ compared to the bulk hematite $(2.1 \mathrm{eV})$. The valence bands due to the oxygen $2 p$ states lies below the Fermi level and the conduction band is dominated by the Fe $3 d$ states. The work function, calculated as the difference between the electrostatic potential in the vacuum region and the Fermi energy of the (0001) surface, is $4.4 \mathrm{eV}$, similar to the results of Wang et al. [62] and Jin et al. [155].

Figure 7. Density of states of the $\alpha-\mathrm{Fe}_{2} \mathrm{O}_{3}(0001)$ surface with GGA+U $=5 \mathrm{eV}$. The Fermi level is set to zero as shown by the dashed line.

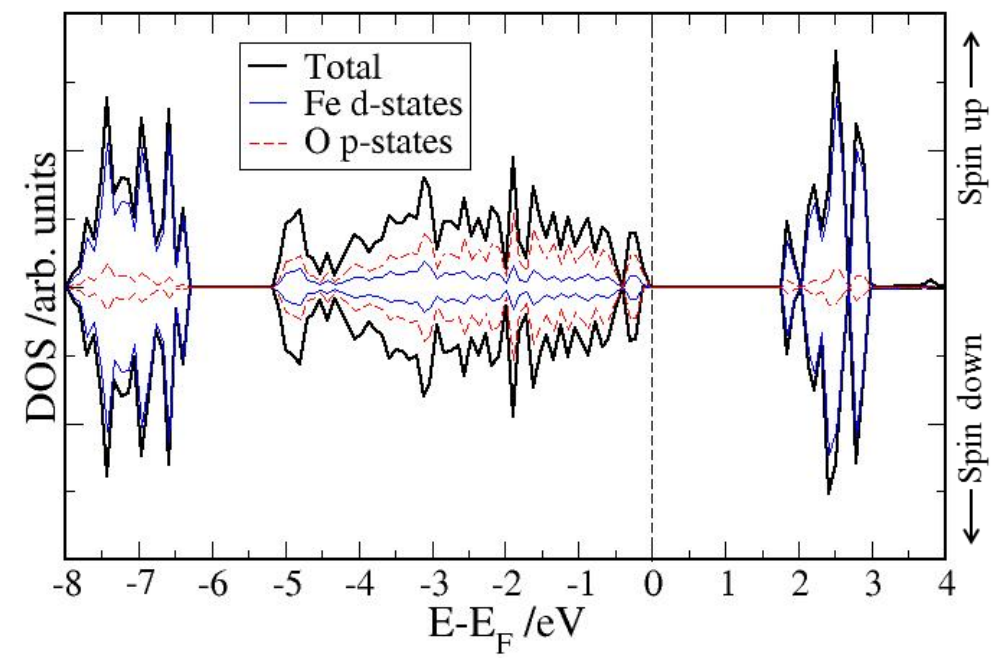

The other surface structure studied in this work is the $\{0112\}$ surface, known to be one of the dominant growth faces exposed on natural $\alpha-\mathrm{Fe}_{2} \mathrm{O}_{3}$ which has been studied in the past by both experimental [156-158] and theoretical groups [63,69,70]. It can have a number of non-dipolar terminations, all of which we have considered, but we have used the most stable termination (see Figure 8) to investigate the adsorption properties of benzene. The topography of this termination is characterized by raised undulating rows of oxygen parallel to the $\mathbf{b}_{\boldsymbol{y}}$ direction and valleys perpendicular to the $\mathbf{a}_{x}$. The top view shows that the surface cations are five-fold coordinated with oxygen, in agreement with the coordination predicted by Henderson et al. [157]. Our geometry optimization calculations show that the clean surface undergoes relaxation within the first five interlayer spacings with percentage relaxation respectively calculated to be $+22 \%,-20 \%,+6 \%,+23 \%$, and $-7 \%$ of the associated bulk layer spacing which is consistent with the results of earlier theoretical results of Wasserman et al. [65] and Lo et al. [69]. The relaxed surface energy is calculated to be $1.92 \mathrm{~J} \mathrm{~m}^{-2}$, which compares well with the results of de Leeuw et al. [63] using different methods (see Table 2). 
Figure 8. Schematic representation of the side and top views of the $\alpha-\mathrm{Fe}_{2} \mathrm{O}_{3}\{0112\}$ surface.
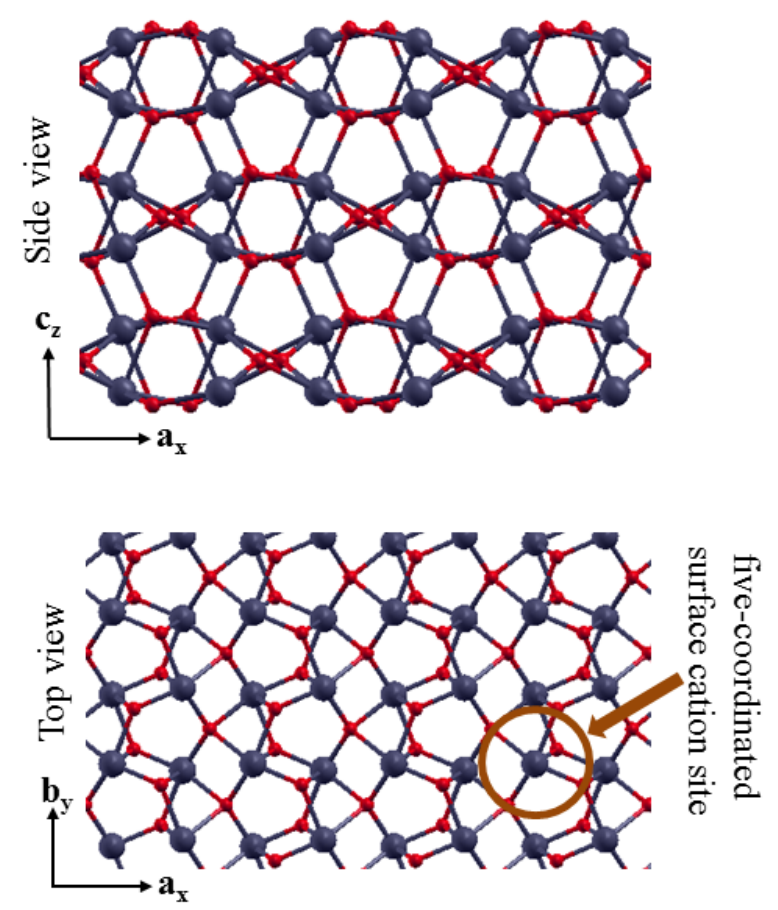

Table 2. Calculated relaxed surface energies for selected surfaces of hematite $\left(\mathrm{J} \mathrm{m}^{-2}\right)$.

\begin{tabular}{|c|c|c|c|c|}
\hline Plane (hkil) & Mackrodt [153] & Reeves and Mann [154] & de Leeuw [63] & This work \\
\hline$\{0001\}-\mathrm{Fe}$ & 1.53 & 2.31 & 1.78 & 1.66 \\
\hline$\{0001\}-\mathrm{O}$ & - & - & 2.63 & 2.59 \\
\hline$\{1010\}$ & 2.36 & 2.35 & 1.99 & 2.19 \\
\hline$\{0112\}$ & 1.47 & - & 1.88 & 1.92 \\
\hline$\{1110\}$ & 2.03 & - & 2.03 & 1.97 \\
\hline$\{1011\}$ & 2.41 & 2.84 & 2.34 & 2.29 \\
\hline$\{1111\}$ & - & - & 1.93 & 2.33 \\
\hline
\end{tabular}

The electronic density of states of the $\alpha-\mathrm{Fe}_{2} \mathrm{O}_{3}\{0112\}$ surface (see Figure 9) remains semi-conducting but the gap width is considerably reduced $(\sim 1.0 \mathrm{eV})$ and the work function is calculated to be $4.1 \mathrm{eV}$. The magnetic moments of the surface Fe atoms are also calculated to be slightly smaller $\left(4.01 \mu_{\beta}\right)$ than $\mathrm{Fe}$ in the bulk hematite $\left(4.23 \mu_{\beta}\right)$. The five-coordination of the surface $\mathrm{Fe}$ atoms compared to the six-coordination in the bulk hematite modifies the hybridization of the $\mathrm{O} 2 p$ and Fe $3 d$ bands and thus affects the local magnetic moments.

In addition to the $\{0001\}$ and $\{0112\}$ surfaces, we have also calculated the surface energies of other low-Miller index surface structures of hematite and compared our results with other theoretical investigations $[63,153,154]$. In Table 2, we present a summary of calculated surface energies of selected low index surface planes. The agreements are generally good and any differences in magnitude are due the different theoretical methods used. 
Figure 9. Density of states of the $\mathrm{Fe}_{2} \mathrm{O}_{3}(0112)$ surface with $\mathrm{GGA}+\mathrm{U}=5 \mathrm{eV}$. The Fermi level is set to zero as shown by the dashed line.

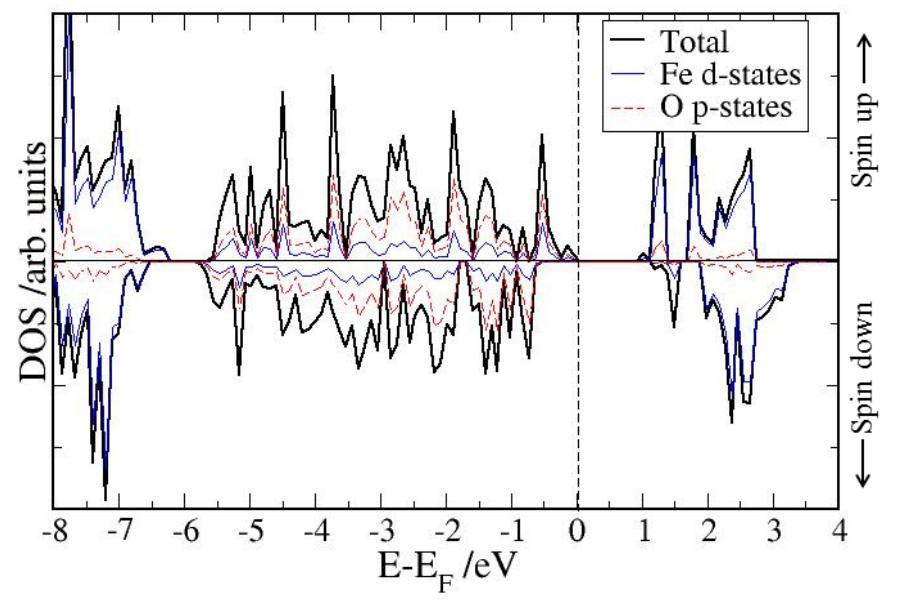

\subsection{Benzene Adsorption}

Before adsorbing the benzene molecule on the different low-Miller index surfaces of hematite, we have calculated its structural parameters in the gas phase and compared them with available experimental data to ensure that our calculations are accurate and reliable. The calculated bond distances and angles are summarized in Table 3 showing excellent agreement with experiment [159].

Table 3. The equilibrium bond distances and angles in benzene calculated in this work and compared with experiment.

\begin{tabular}{ccc}
\hline Parameters & Experiment [159] & This work \\
\hline$d(\mathrm{C}-\mathrm{H}) / \AA$ & 1.101 & 1.091 \\
$d(\mathrm{C}-\mathrm{C}) / \AA$ & 1.399 & 1.400 \\
$<\mathrm{C}-\mathrm{C}-\mathrm{C} /^{\circ}$ & 120.0 & 119.9 \\
$<\mathrm{C}-\mathrm{C}-\mathrm{H} /^{\circ}$ & 120.0 & 120.0 \\
\hline
\end{tabular}

The adsorption characteristics of benzene on the (0001) and (0112) $\alpha-\mathrm{Fe}_{2} \mathrm{O}_{3}$ surfaces were then obtained by determining the preferred adsorption geometries and their corresponding adsorption energies calculated from the relation below:

$$
E_{\text {ads }}=E_{\text {surf }+C_{6} H_{6}}-\left(E_{\text {surf }}+E_{C_{6} H_{6}}\right)
$$

where $E_{s u r f+C_{6} H_{6}}$ is the total energy of the adsorbate-substrate system, $E_{\text {surf }}$ is the energy of the clean surface slab and $E_{C_{6} H_{6}}$ is the energy of the isolated benzene molecule. A negative value for the adsorption energy means that the corresponding adsorbed state is thermodynamically more stable than the unbound state.

The optimized adsorption geometries of benzene on the (0001) surface are shown in Figure 10 and the adsorption parameters (binding energy, bond distances and bond angles) are summarized in Table 4. The interaction of the benzene molecule in all three adsorption geometries at the $\{0001\}$ surface does not involve direct chemical bond formation with atoms of the oxide substrate, suggesting that van der Waals interactions (vdW) play an important role in stabilizing the adsorbed benzene 
molecule. The energetically most stable adsorption geometry is calculated to be the parallel adsorption geometry with a total adsorption energy of $-1.17 \mathrm{eV}$ (contribution of the van der Waals interactions: $E_{\mathrm{vdW}}=-0.44 \mathrm{eV}$ ). In the parallel adsorption geometry, the benzene ring lies symmetrically around the interacting surface $\mathrm{Fe}$ atom at an almost equivalent $\mathrm{C}-\mathrm{Fe}$ distance $(2.301 \AA)$; see the top view of Figure 10a. The delocalization of electrons within the aromatic ring favors this adsorption geometry, where the benzene molecule interacts with the surface Fe atom through $\pi$-bonding. The adsorbed benzene molecule remains planar without significant changes in the internal conformations. The $\mathrm{C}-\mathrm{H}$ bonds are slightly bent towards the oxide surface and the interacting surface Fe atom is displaced upwards by $0.123 \AA$ relative to its position on the naked surface.

We have also identified two other stable adsorption geometries, namely slant and vertical adsorption geometries (see Figure 10b,c). In the slant adsorption geometry, the benzene molecule lies at an angle of $\sim 45^{\circ}$ to the surface normal interacting through one carbon-iron $\pi$-bond $(2.361 \AA)$ with an adsorption energy of $-0.79 \mathrm{eV}\left(E_{\mathrm{vdW}}=-0.26 \mathrm{eV}\right)$. The benzene molecule remained planar in the adsorbed state without significant changes in its internal bond distance and angles. The weakest interaction is predicted in the vertical adsorption geometry where the benzene molecule only interacts with the surface oxygen atoms through weak hydrogen bonding. The adsorption energy of the vertical geometry is calculated to be $-0.28 \mathrm{eV}\left(E_{\mathrm{vdW}}=-0.17 \mathrm{eV}\right)$ suggesting that the vertical adsorption geometry is stabilized mainly by the weak van der Waals forces. The closest $\mathrm{O}-\mathrm{H}$ bond distance is calculated to be $2.682 \AA$.

Figure 10. Relaxed adsorption geometries of the benzene on $\alpha-\mathrm{Fe}_{2} \mathrm{O}_{3}(0001)$ in (a) parallel; (b) slant and (c) vertical adsorption modes respectively. The top (left) and side (right) views are shown. Color scheme: $\mathrm{Fe}=$ grey; $\mathrm{O}=$ red; $\mathrm{C}=$ green and $\mathrm{H}=$ white.

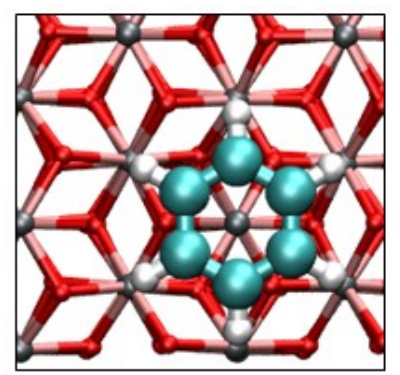

(a)
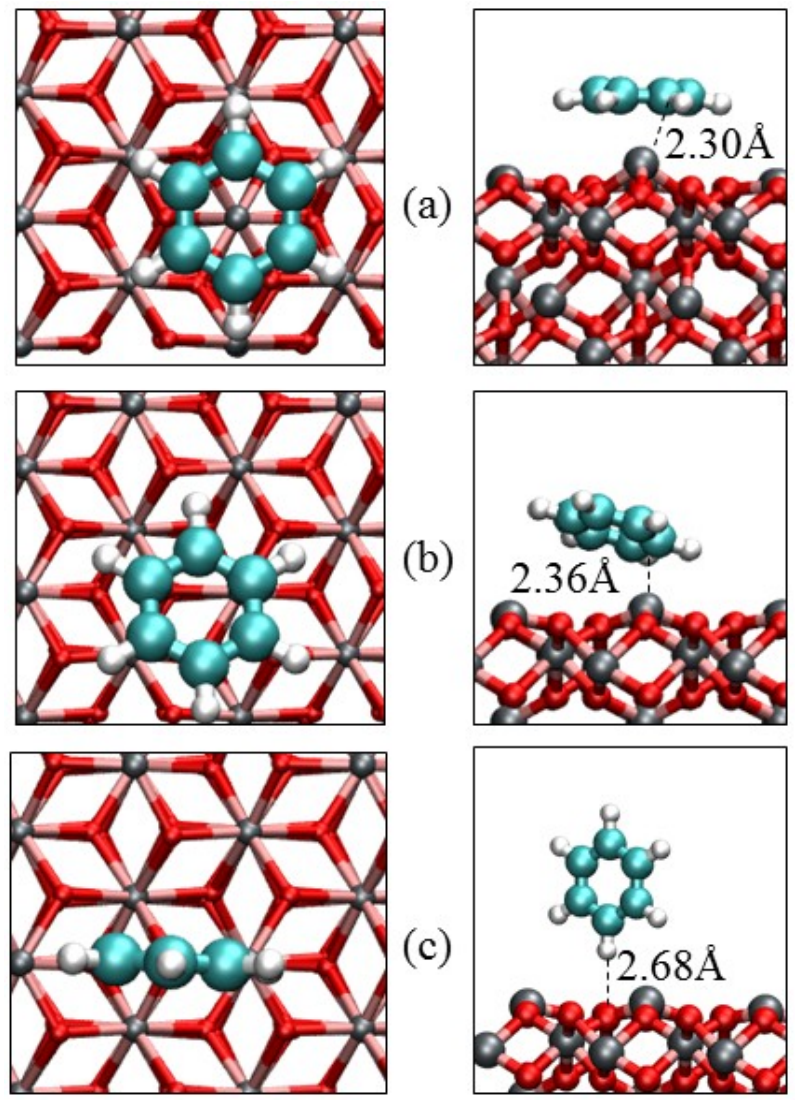
Table 4. Adsorption energies and structure parameters of benzene adsorbed on the (0001) and (0112) $\alpha-\mathrm{Fe}_{2} \mathrm{O}_{3}$ surfaces. $E_{\text {ads }}$ and $Q_{\text {mol }}$ denote respectively the adsorption energy and charge on the adsorbed benzene molecule.

\begin{tabular}{cccccc}
\hline \multirow{2}{*}{ Parameters } & \multicolumn{3}{c}{$\boldsymbol{\alpha}-\mathrm{Fe}_{2} \mathbf{O}_{\mathbf{3}}(\mathbf{0 0 0 1})$} & \multicolumn{2}{c}{$\boldsymbol{\alpha - F e} \mathbf{O}_{\mathbf{3}}(\mathbf{0 1} 1 \mathbf{2})$} \\
\cline { 2 - 6 } & Parallel & Slant & Vertical & Parallel & Vertical \\
\hline$E_{\text {ads }} / \mathrm{eV}$ & -1.17 & -0.79 & -0.28 & -1.52 & -0.41 \\
$Q_{\mathrm{mol}} / \mathrm{e}^{-}$ & -0.07 & -0.05 & 0.00 & -0.23 & -0.00 \\
$\mathrm{Fe}-\mathrm{C} / \AA$ & 2.301 & 2.363 & - & 1.952 & - \\
$\mathrm{O}-\mathrm{C} / \AA$ & 3.001 & 3.065 & - & 1.631 & - \\
$\mathrm{O}-\mathrm{H} / \AA$ & 3.106 & 2.701 & 2.682 & 3.001 & 2.300 \\
$d(\mathrm{C}-\mathrm{H}) / \AA$ & 1.093 & 1.091 & 1.090 & 1.104 & 1.091 \\
$d(\mathrm{C}-\mathrm{C}) / \AA$ & 1.421 & 1.411 & 1.401 & 1.503 & 1.401 \\
$<\mathrm{C}-\mathrm{C}-\mathrm{C} /{ }^{\circ}$ & 119.9 & 119.8 & 120.0 & 116.9 & 120.0 \\
$<\mathrm{C}-\mathrm{C}-\mathrm{H} /{ }^{\circ}$ & 120.3 & 120.2 & 120.0 & 117.4 & 119.9 \\
\hline
\end{tabular}

The benzene molecule is found to adsorb relatively stronger on the $(0112)$ surface than on the (0001) surface. Unlike on the (0001) surface, the parallel adsorption geometry on the (0112) surface involves direct chemical bond formation between the carbon atoms of the benzene molecule and the surface atoms, giving a stronger interaction with an adsorption energy of $-1.52 \mathrm{eV}\left(E_{\mathrm{vdW}}=-0.48 \mathrm{eV}\right)$. The $\mathrm{C}-\mathrm{Fe}$ and $\mathrm{C}-\mathrm{O}$ bond distances are respectively calculated to be $1.952 \AA$ and $1.631 \AA$. The interaction results in distortion of the benzene ring with the hydrogen atoms around the bound region slightly displaced upwards, causing the $\mathrm{C}-\mathrm{H}$ bonds to elongate $(1.091 \rightarrow 1.104 \AA)$. The $\mathrm{C}-\mathrm{C}$ bond distance within the bound region is also slightly elongated $(1.400 \rightarrow 1.503 \AA)$. The vertical adsorption geometry gave a weak interaction with an adsorption energy of $-0.41\left(E_{\mathrm{vdW}}=-0.23 \mathrm{eV}\right)$. In the vertical geometry, the benzene molecule only interacts through weak hydrogen bonds with the surface oxygen atoms as shown in Figure $11 \mathrm{~b}$ and is further stabilized by van der Waals interactions.

When we compare our results with benzene adsorption at the goethite $(\mathrm{FeOOH})$ surface $[29,88]$, we note that there the benzene molecule forms relatively weak surface complexes due the presence of the surface $\mathrm{OH}$ groups. The origin of these interactions is in the polarization of the $\pi$-system by the polar $\mathrm{OH}$ groups and in the formation of weak hydrogen-bonds where the $\pi$-system acts as a proton acceptor. The mechanism of benzene interaction with the hematite surfaces, on the other hand, involves cation- $\pi$ interactions between the $\pi$-electrons of the aromatic rings and surface cations for the flat adsorption geometries, thereby giving a much stronger interaction. In the aqueous phase, the benzene molecule will have to compete with water molecules for the cationic sorption sites of minerals and it is often the case that water molecules bind more strongly to the active surface sites, thereby, preventing the benzene from having direct access to these active sites; as a result the benzene forms relatively weak outer-sphere surface complexes via long hydrogen-bonds, where the $\pi$-system acts as a proton acceptor, as was shown on the goethite surface. We therefore expect that the presence of water molecules at the hematite surfaces will weaken the strength of interaction, given the fact that the cation- $\pi$ interactions will become weaker hydrogen-bonds dominated by Van der Waals interactions. 
Figure 11. Relaxed adsorption geometries of the benzene on $\alpha-\mathrm{Fe}_{2} \mathrm{O}_{3}(0112)$. The parallel and vertical geometries are shown in (a) and (b) respectively. The top (left) and side (right) views are shown. Color scheme: $\mathrm{Fe}=$ grey; $\mathrm{O}=$ red; $\mathrm{C}=$ green and $\mathrm{H}=$ white.

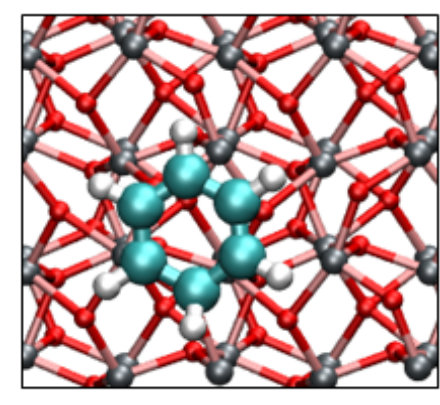

(a)
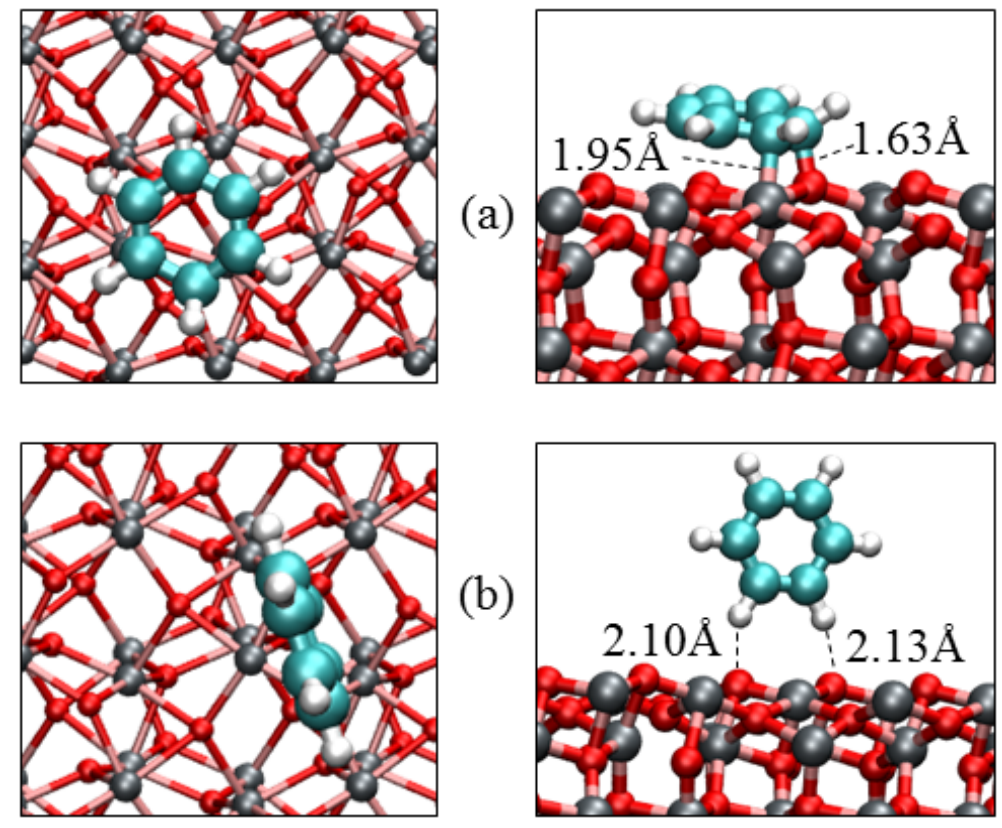

\section{Electronic Structures}

In order to evaluate the effect of benzene adsorption on the electronic structures of the hematite surfaces, we have plotted the local electronic density of states (LDOS) for the topmost iron and oxygen atoms in the most stable adsorbed complexes on the (0001) and (0112) surfaces and compared these with those of the clean surfaces as shown in Figures 12 and 13. The LDOS of the topmost Fe and O atoms on the clean (0001) surface contains broad surface valence and conduction bands separated by a wide band gap. After adsorption of the benzene, the conduction band edge is shifted towards the valence bands considerably reducing the band gap, which could favor an easier electron transfer across the gap. On the $(0112)$, the Fe $d$-states even cross the Fermi level suggesting metallic behavior, causing the stronger interaction of the benzene molecule with this surface. While there is evidence of local electron rearrangements within the adsorbate-substrate system, the overall charge transfer from the hematite surfaces to the adsorbed benzene molecule as estimated from the Bader partition scheme [160] is very small.

While the charge gained by the benzene molecule at the (0001) surface is $<0.1 \mathrm{e}^{-}$, at the (0112) surface, where the benzene molecule is chemisorbed in the parallel mode, it gained $0.23 \mathrm{e}^{-}$from the interacting surface atoms upon adsorption. To gain further insight into the local electron rearrangement within the $\mathrm{C}_{6} \mathrm{H}_{6} / \alpha-\mathrm{Fe}_{2} \mathrm{O}_{3}$ systems, we have analyzed the differential electron density $(\Delta \rho)$ of the most stable adsorption geometries. This quantity is obtained by subtracting from the electron density of the $\mathrm{C}_{6} \mathrm{H}_{6} / \alpha-\mathrm{Fe}_{2} \mathrm{O}_{3}$ (hkil) system, both the electron density of the clean surface and that of an isolated benzene layer as represented in Equation (2).

$$
\rho_{\text {transfer }}=\rho_{\text {surf }+C_{6} H_{6}}-\left(\rho_{\text {surf }}+\rho_{C_{6} H_{6}}\right)
$$


Figure 12. The electronic local density of states (LDOS) of the clean and benzene covered topmost surface (a) $\mathrm{Fe}$ and (b) $\mathrm{O}$ atoms of the $\alpha-\mathrm{Fe}_{2} \mathrm{O}_{3}(0001)$. The Fermi level is set to zero as shown by the dashed line.

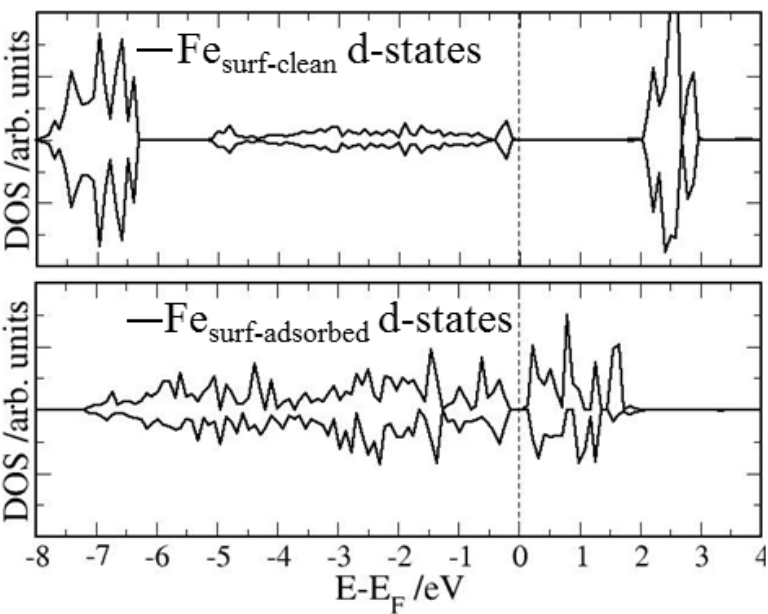

(a)

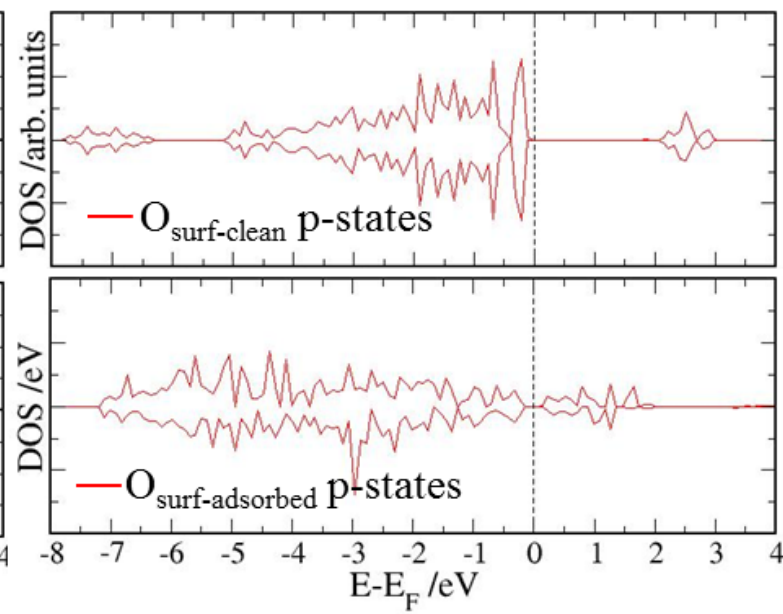

(b)

Figure 13. The electronic local density of states (LDOS) of the clean and benzene covered topmost surface (a) Fe and (b) $\mathrm{O}$ atoms of the $\alpha-\mathrm{Fe}_{2} \mathrm{O}_{3}(0112)$. The Fermi level is set to zero as shown by the dashed line.
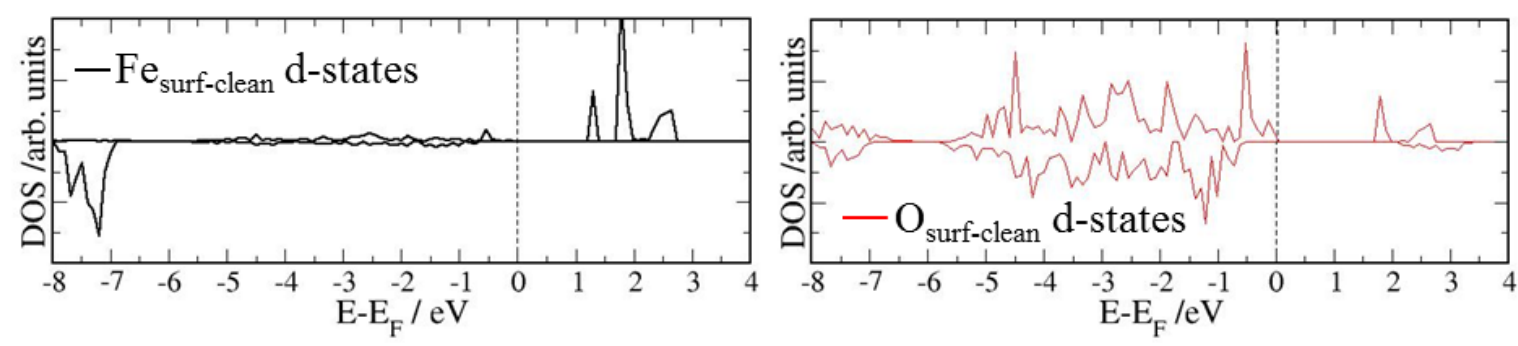

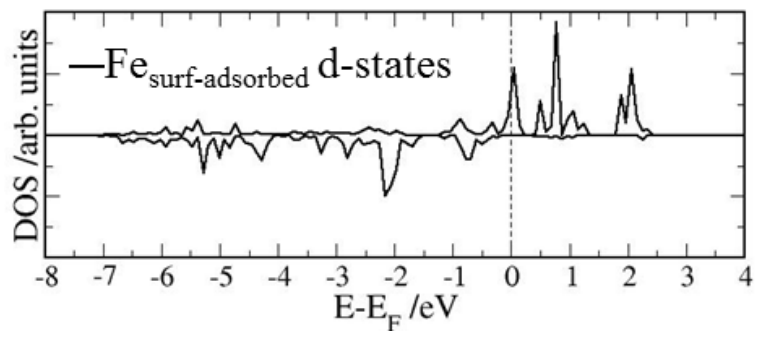

(a)

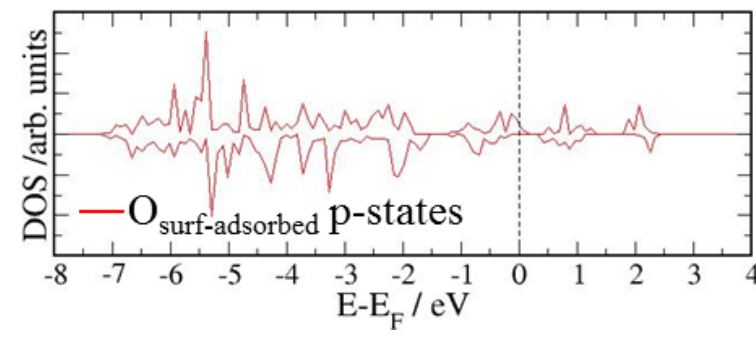

(b)

The latter two quantities in brackets were calculated using the same geometry as the total surface-adsorbate system. In this way, the presentation highlights the electronic structure and bond formation. In Figure 14, an isovalue of $\pm 0.02 \mathrm{e} / \AA^{3}$ has been used to show that there is an accumulation of charge density within the interaction/bonding regions. Evidence of bond formation at the (0112) surface is clearly shown by the accumulation of electron density within the $\mathrm{C}-\mathrm{Fe}$ and $\mathrm{C}-\mathrm{O}$ bonding regions and the physisorption at the (0001) is also evident.

Finally, we have analyzed and summarized in Table 5 the effect of benzene adsorption on the magnetic properties of the surface Fe atoms with which the benzene molecule interacts. In general we found that the adsorbed benzene molecule led to a decrease in the magnetic moments of the interacting 
surface Fe atoms. The effect is more pronounced in the parallel adsorption modes, where the molecule interacts most strongly with the hematite surfaces. Similar results have been obtained on nickel clusters where adsorbed carbon monoxide and hydrogen led to a decrease of the surface Ni magnetic moments [161]. It is, however, in contrast to the situation observed at the surfaces of Fe crystals, where oxygen adsorption leads to enhancement of magnetism on the surface layer atoms [162]. In the vertical adsorption modes where the benzene molecule interacts less with the surface Fe atoms, the magnetic moments do not change significantly. The changes in the electronic and magnetic properties of the hematite surface structures upon benzene adsorption can be attributed to the electron donation from the benzene molecule to the minority states of the surface Fe atoms, and the back-donation from majority states of the surface Fe atoms into anti-bonding molecular orbitals, which modifies the shape of the bands and character of the $\mathrm{O} 2 p$ and $\mathrm{Fe} 3 d$ hybridization.

Figure 14. Charge density difference plot relative to $\mathrm{C}_{6} \mathrm{H}_{6}$ adsorbed on (a) (0001) and (b) $(0112) \alpha-\mathrm{Fe}_{2} \mathrm{O}_{3}$ surfaces. The orange contours indicate electron density increase by 0.02 electrons $/ \AA^{3}$ and blue contours indicate electron density decrease by 0.02 electrons $/ \AA^{3}$.
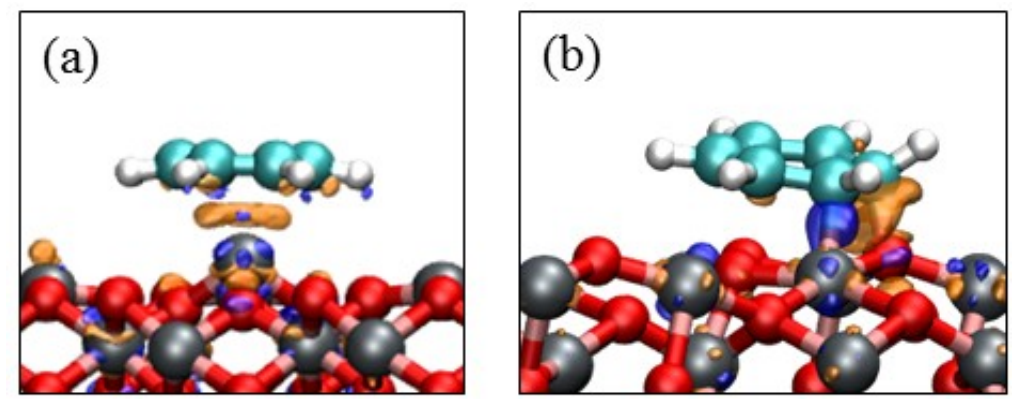

Table 5. The magnetic moments of the interacting surface Fe atoms before and after adsorption of benzene. The bulk hematite Fe magnetic moment is $4.23 \mu_{\beta}$.

\begin{tabular}{cccc}
\hline \multirow{2}{*}{ Surface } & \multirow{2}{*}{ Adsorption mode } & \multicolumn{2}{c}{ Interacting Fe magnetic moment $\left(\boldsymbol{\mu}_{\boldsymbol{\beta}}\right)$} \\
\cline { 3 - 4 } & & Clean surface & Adsorbed surface \\
\hline \multirow{2}{*}{$(0001)$} & Parallel & 3.97 & 3.65 \\
& Slant & 3.97 & 3.78 \\
& Vertical & 3.97 & 3.91 \\
\hline \multirow{2}{*}{$(0112)$} & Parallel & 4.01 & 3.49 \\
& Vertical & 4.01 & 3.98 \\
\hline
\end{tabular}

\section{Summary and Conclusions}

We have investigated the adsorption properties of benzene on the (0001) and (0112) surfaces of hematite using ab initio calculations within the DFT-GGA+U formalism under vacuum conditions. We have shown that the inclusion of the on-site Coulomb repulsion $\left(U_{\text {eff }}\right)$ to the DFT Hamiltonian provides an accurate description of the electronic and magnetic properties of hematite. For the adsorption of a single benzene molecule on the (0001) and (0112) surfaces of hematite, we found that the parallel adsorption geometries are energetically more stable than the vertical geometries. The predicted adsorption geometries at the (0001) surface suggest that van der Waals interactions are important in stabilizing the benzene molecule at the surface. The benzene molecule is bound to the (011 2$)$ surface 
via cation- $\pi$ interactions between the $\pi$-electrons of aromatic rings and surface cations giving a much stronger interaction. At both surfaces, the adsorbed benzene molecules remain planar with only small changes in the bond distances and angles. Analyses of the electronic structures reveal that upon benzene adsorption, the conduction band edge of the surface atoms is shifted towards the valence bands, thereby considerably reducing the band gap. Adsorption of the benzene molecule at the hematite surfaces also leads to a decrease in the surface Fe magnetic moments. Although our results provide fundamental and general insight into the electronic and magnetic properties of aromatic molecules adsorbed on iron oxide surfaces under vacuum conditions, we suggest that future calculations should incorporate the effect of water, as sorption of organic pollutants normally occurs in aqueous environments, where the aromatic molecules have to compete with water molecules and other adsorbates for the active binding sites on the mineral surface. Our calculated interatomic distances for the adsorption of isolated benzene molecule on the hematite surface under vacuum conditions could, however, serve towards the development of reliable forcefields that can be employed in classical MD simulations to simulate complex systems, including single and multiple organic adsorbates and the effect of water, which will provide a more realistic description of the hematite-water-benzene system.

\section{Acknowledgments}

Nelson Y. Dzade acknowledges University College London for an Overseas Research Scholarship and Nora H. de Leeuw acknowledges the Engineering and Physical Sciences Research Council for funding (Grant No. EP/H046313/1). This work made use of the facilities of HECToR, the UK's national high-performance computing service via our membership of the UK's HPC Materials Chemistry Consortium, which is funded by the EPSRC (EP/F067496). The authors also acknowledge the use of the UCL@Legion High Performance Computing Facility, and associated support services, in the completion of this work.

\section{Conflicts of Interest}

The authors declare no conflict of interest.

\section{References}

1. Cornell, R.M.; Schwertmann, U. Iron Oxides in the Laboratory: Preparation and Characterization, 2nd ed.; Wiley-VCH: New York, NY, USA, 2000.

2. Cornell, R.M.; Schwertmann, U. The Iron Oxides: Structure, Properties, Reactions, Occurrences, and Uses, 2nd ed.; Wiley-VCH: New York, NY, USA, 2003.

3. Teja, A.S.; Koh, P.Y. Synthesis, properties, and applications of magnetic iron oxide nanoparticles. Prog. Cryst. Growth Charact. Mater. 2009, 55, 22-45.

4. Mahmoudi, M.; Simchi, I.; Imani, M. Recent advances in surface engineering of superparamagnetic iron oxide nanoparticles for biomedical applications. J. Iran. Chem. Soc. 2010, 7, S1-S27.

5. Wang, G.; Liu, T.; Luo, Y.; Zhao, Y.; Ren, Z.; Bai, J.; Wang, H. Preparation of $\mathrm{Fe}_{2} \mathrm{O}_{3}$ /graphene composite and its electrochemical performance as an anode material for lithium ion batteries. J. Alloys Compd. 2011, 509, L216-L220. 
6. Singh, J.; Srivastava, M.; Dutta, J.; Dutta, P.K. Preparation and properties of hybrid monodispersed magnetic $\alpha-\mathrm{Fe}_{2} \mathrm{O}_{3}$ based chitosan nanocomposite film for industrial and biomedical applications. Int. J. Biol. Macromol. 2011, 48, 170-176.

7. Hassan, M.F.; Guo, Z.; Chen, Z.; Liu, H. $\alpha-\mathrm{Fe}_{2} \mathrm{O}_{3}$ as an anode material with capacity rise and high rate capability for lithium-ion batteries. Mater. Res. Bull. 2011, 46, 858-864.

8. Gupta, A.K.; Gupta, M. Synthesis and surface engineering of iron oxide nanoparticles for biomedical applications. Biomaterials 2005, 26, 3995-4021.

9. Twigg, M.V. Catalyst Handbook; Wolfe Publishing: London, UK, 1989.

10. Xu, L.; Bao, S.; O’Brien, R.J.; Houpt, D.J.; Davis, B.H. Iron fischer-tropsch catalysis-properties of an ultrafine iron oxide catalyst. Fuel Sci. Technol. Int. 1994, 12, 1323-1353.

11. Jung, H.; Thomson, W.J. Dynamic X-ray diffraction study of an unsupported iron catalyst in Fischer-Tropsch synthesis. J. Catal. 1993, 139, 375-382.

12. Appl, M. Ammonia, 2. Production Processes. In Ullmann's Encyclopedia of Industrial Chemistry; Wiley-VCH: Hoboken, NJ, USA, 2011; Volume 3, pp. 227-261.

13. Lei, Y.; Cant, N.W.; Trimm, D.L. Activity patterns for the water gas shift reaction over supported precious metal catalysts. Catal. Lett. 2005, 103, 133-136.

14. Huang, C.S.; Xu, L.; Davis, B.H. Fischer-Tropsch synthesis: Impact of pretreatment of ultrafine iron oxide upon catalyst structure and selectivity. Fuel Sci. Technol. Int. 1993, 11, 639-664.

15. Mimura, N.; Takahara, I.; Ando, M. Dehydrogenation of ethylbenzene over iron oxide-based catalyst in the presence of carbon dioxide. Catal. Today 1998, 45, 61-64.

16. Zscherpel, D.; Weiss, W.; Schlogl, R. Adsorption and dehydrogenation of ethylbenzene on ultrathin iron oxide model catalyst films. Surf. Sci. 1997, 382, 326-335.

17. Chang, J.S.; Park, S.E.; Park, M.S. Beneficial effect of carbon dioxide in dehydrogenation of ethylbenzene to styrene over zeolite-supported iron oxide catalyst. Chem. Lett. 1997, 26, 1123-1124.

18. Mendoza, E.A.; Sunil, D.; Wolkow, E.; Gafney, H.D.; Rafailovich, M.H.; Sokolov, J.; Long, G.G.; Jemian, P.R.; Schwartz, S.A.; Wilkens, B.J. Effect of photodeposited iron oxide and tin oxide on the consolidation of porous Vycor glass. Appl. Phys. Lett. 1990, 57, 209-211.

19. Morsi, M.M.; El-Shennawi, A.W.A. Joint effect of gamma irradiation and $\mathrm{TiO}_{2}$ nucleation on the crystallization of $\left(\mathrm{Li}_{2}, \mathrm{R}\right) \mathrm{O}$ aluminosilicate glass with and without iron oxide addition. Ceram. Int. 1993, 19, 333-338.

20. Burkhard, D.J.M. Elastic properties of alkali silicate glasses with iron oxide: Relation to glass structure. Solid State Commun. 1997, 101, 903-907.

21. Suber, L.; Imperatori, P.; Ausanio, G.; Fabbri, F.; Hofmeister, H. Synthesis, morphology, and magnetic characterization of iron oxide nanowires and nanotubes. J. Phys. Chem. B 2005, 109, 7103-7109.

22. Xiong, Y.; Ye, J.; Gu, X.; Chen, Q. Synthesis and magnetic properties of iron oxide nanoparticles/C and $\alpha$-Fe/iron oxide nanoparticles/C composites. J. Magn. Magn. Mater. 2008, 320, 107-112.

23. Fujishiro, Y.; Uchida, S.; Sato, T. Synthesis and photochemical properties of semiconductor pillared layered compounds. Int. J. Inorg. Mater. 1999, 1, 67-72.

24. Peng, X.; Qian, X.; Mao, H.; Wang, A.Y.; Chen, Z.; Nie, S.; Shin, D.M. Targeted magnetic iron oxide nanoparticles for tumor imaging and therapy. Int. J. Nanomed. 2008, 3, 311-321. 
25. Yu, M.; Park, J.; Jeong, Y.Y.; Moon, W.K.; Jon, S. Integrin-targeting thermally cross-linked superparamagnetic iron oxide nanoparticles for combined cancer imaging and drug delivery. Nanotechnology 2010, 21, doi:10.1088/0957-4484/21/41/415102.

26. Waychunas, G.A.; Kim, C.S.; Banfield, J.F. Nanoparticulate iron oxide minerals in soils and sediments: Unique properties and contaminant scavenging mechanisms. J. Nanopart. Res. 2005, 7, 409-433.

27. Nassar, N.N. Iron Oxide Nanoadsorbents for Removal of Various Pollutants from Wastewater: An Overview. In Application of Adsorbents for Water Pollution Control; Bentham Science Publishers: Sharjah, United Arab Emirates, 2012; pp. 81-118.

28. Xu, P.; Zeng, G.M.; Huang, D.L.; Feng, C.L.; Hu, S.; Zhao, M.H.; Lai, C.; Wei, Z.; Huang, C.; Xie, G.X.; et al. Use of iron oxide nanomaterials in wastewater treatment: A review. Sci. Total Environ. 2012, 424, 1-10.

29. Tunega, D.; Gerzabek, M.H.; Haberhauer, G.; Totsched, K.U.; Lischka, H. Model study on sorption of polycyclic aromatic hydrocarbons to goethite. J. Colloid Interface Sci. 2009, 330, 244-249.

30. Rebhun, M.; Kalabo, R.; Grossman, L.; Manka, J.; Rav-Acha, C. Sorption of organics on clay and synthetic humic-clay complexes simulating aquifer processes. Water Res. 1992, 26, 79-84.

31. Lijestrand, M.H.; Lo, I.M.-C.; Shimizu, Y. Sorption of humic materials onto inorganic surfaces for the mitigation of facilitated pollutant transport processes. Water Sci. Technol. 1992, 26, 1221-1228.

32. Knezovich, J.P.; Harrison, F.L.; Wilhelm, R.G. The bioavailability of sediment-sorbed organic chemicals. Water Air Soil Pollut. 1987, 32, 233-245.

33. Fendorf, S.; Eick, M.J.; Grossl, P.; Sparks, D.L. Arsenate and chromate retention mechanisms on goethite. 1. Surf. Struct. Environ. Sci. Technol. 1997, 31, 315-320.

34. Waychunas, G.A.; Rea, B.A.; Fuller, C.C.; Davis, J.A. Surface chemistry of ferrihydrite: Part 1. EXAFS studies of the geometry of coprecipitated and adsorbed arsenate. Geochim. Cosmochim. Acta 1993, 57, 2251-2269.

35. Waychunas, G.A.; Davis, J.A.; Fuller, C.C. Geometry of sorbed arsenate on ferrihydrite and crystalline FeOOH: Re-evaluation of EXAFS results and topological factors in predicting sorbate geometry, and evidence for monodentate complexes. Geochim. Cosmochim. Acta 1995, 59, $3655-3661$.

36. Hsia, T.H.; Lo, S.L.; Lin, C.F.; Lee, D.Y. Characterization of arsenate adsorption on hydrous iron oxide using chemical and physical methods. Colloids Surf. A Physicochem. Eng. Asp. 1994, 85, $1-7$.

37. Sun, X.H.; Doner, H.E. An investigation of arsenate and arsenite bonding structures on goethite by FTIR. Soil Sci. 1996, 161, 865-872.

38. Manning, B.A.; Fendorf, S.E.; Goldberg, S. Surface structures and stability of arsenic(III) on goethite: Spectroscopic evidence for inner-sphere complexes. Environ. Sci. Technol. 1998, 32, 2383-2388.

39. Manning, B.A.; Hunt, M.L.; Amrhein, C.; Yarmoff, J.A. Arsenic(III) and Arsenic(V) reactions with zerovalent iron corrosion products. Environ. Sci. Technol. 2002, 36, 5455-5546.

40. Foster, A.L.; Brown, G.E., Jr.; Tingle, T.N.; Parks, G.A. Quantitative arsenic speciation in mine tailings using X-ray absorption spectroscopy. Am. Mineral. 1998, 83, 553-568. 
41. Farquhar, M.L.; Charnock, J.M.; Livens, F.R.; Vaughan, D.J. Mechanisms of arsenic uptake from aqueous solution by interaction with goethite, lepidocrocite, mackinawite, and pyrite: An X-ray absorption spectroscopy study. Environ. Sci. Technol. 2002, 36, 1757-1762.

42. Ona-Nguema, G.; Morin, G.; Juillot, F.; Brown, G.E., Jr.; Calas, G. EXAFS analysis of arsenite adsorption onto two-line ferrihydrite, hematite, goethite, and lepidocrocite. Environ. Sci. Technol. 2005, 39, 9147-9155.

43. Wang, Y.; Morin, G.; Ona-Nguema, G.; Juillot, J.; Guyot, F.; Calas, G.; Brown, G.E., Jr. Evidence for different surface speciation of arsenite and arsenate on green rust: An EXAFS and XANES study. Environ. Sci. Technol. 2010, 44, 109-115.

44. Goldberg, S.; Johnston, C.T. Mechanisms of arsenic adsorption on amorphous oxides evaluated using macroscopic measurements, vibrational spectroscopy, and surface complexation modelling. J. Colloid Interface Sci. 2001, 234, 204-216.

45. Wu, H.; Lin, Y.; Wu, J.; Zeng, L.; Zeng, D.; Du, J. Surface adsorption of iron oxide minerals for phenol and dissolved organic matter. Earth Sci. Front. 2008, 15, 133-141.

46. McBride, M.B.; Kung, K.H. Adsorption of phenol substituted phenols by iron-oxides. Environ. Toxicol. Chem. 1991, 10, 441-448.

47. Beentjes, P.C.J.; Brand, J.D.; Dewit, J.H.W. Interaction of ester and acid groups containing organic compounds with iron oxide surfaces. J. Adhes. Sci. Technol. 2006, 20, 1-18.

48. Parfitt, R.L.; Farmer, V.C.; Russell, J.D. Adsorption on hydrous oxides. 1. Oxalate and benzoate on goethite. J. Soil Sci. 1977, 28, 29-39.

49. Hwang, Y.K.; Lenhart, J.J. Surface complexation modeling of dual-mode adsorption of organic acids: Phthalic acid adsorption onto hematite. J. Colloid Interface Sci. 2009, 336, 200-207.

50. Angove, M.J.; Fernandes, M.B.; Ikhsan, J. The sorption of anthracene onto goethite and kaolinite in the presence of some benzene carboxylic acids. J. Colloid Interface Sci. 2002, 247, 282-289.

51. Boily, J.-F.; Fein, J.B. Adsorption of $\mathrm{Pb}(\mathrm{II})$ and benzenecarboxylates onto corundum. Chem. Geol. 1998, 148, 157-175.

52. Das, M.R.; Bordoloi, D.; Borthakur, P.C.; Mahiuddin, S. Kinetics and adsorption of benzoate and salicylate at the natural hematite-water interface. Colloids Surf. A Physicochem. Eng. Asp. 2005, 254, 49-55.

53. Huda, M.N.; Walsh, Y.; Yan, Y.; Wei, S.-H.; Al-Jassim, M.N. Electronic, structural, and magnetic effects of 3d transition metals in hematite. J. Appl. Phys. 2010, 107, doi:10.1063/1.3432736.

54. Rohrbach, A.; Hafner, J.; Kresse, G. Ab initio study of the (0001) surfaces of hematite and chromia: Influence of strong electronic correlations. Phys. Rev. $B$ 2004, 70, doi:10.1103/PhysRevB.70.125426.

55. Rollmann, G.; Rohrbach, A.; Entel, P.; Hafner, J. First-principles calculation of the structure and magnetic phases of hematite. Phys. Rev. B 2004, 69, doi:10.1103/PhysRevB.69.165107.

56. Bandyopadhyay, A.; Velev, J.; Butler, W.H.; Sarker, S.K.; Bengone, O. Effect of electron correlations on the electronic and magnetic structure of Ti-doped $\alpha$-hematite. Phys. Rev. B. 2004, 69, 174429:1-174429:8.

57. Lee, J.; Han, S. Thermodynamics of native point defects in $\alpha-\mathrm{Fe}_{2} \mathrm{O}_{3}$ : An ab initio study. Phys. Chem. Chem. Phys. 2013, 15, 18906-18914. 
58. Rivera, R.; Pinto, H.P.; Stashans, A.; Piedra, L. Density functional theory study of Al-doped hematite. Phys. Scr. 2012, 85, doi:10.1088/0031-8949/85/01/015602.

59. Meng, X.Y.; Qin, G.W.; Li, S.; Wen, X.H.; Ren, Y.P.; Pei, W.L.; Zuo, L. Enhanced photoelectrochemical activity for $\mathrm{Cu}$ and $\mathrm{Ti}$ doped hematite: The first principles calculations. Appl. Phys. Lett. 2011, 98, doi:10.1063/1.3567766.

60. Liao, P.; Toroker, M.C.; Carter, E.A. Electron transport in pure and doped hematite. Nano Lett. 2011, 11, 1775-1781.

61. Trainor, T.P.; Chaka, A.M.; Eng, P.J.; Newville, M.; Waychunas, C.A.; Catalano, J.C.; Brown, G.E., Jr. Structure and reactivity of the hydrated hematite (0001) surface. Surf. Sci. 2004, 573, 204-224.

62. Wang, X.G.; Weiss, W.; Shaikhutdinov, S.K.; Ritter, M.; Petersen, M.; Wagner, F.; Schlögl, R.; Scheffler, M. The hematite $\left(\alpha-\mathrm{Fe}_{2} \mathrm{O}_{3}\right)(0001)$ surface: Evidence for domains of distinct chemistry. Phys. Rev. Lett. 1998, 81, 1038-1041.

63. De Leeuw, N.H.; Cooper, T.G. Surface simulation studies of the hydration of white rust $\mathrm{Fe}(\mathrm{OH})_{2}$, goethite $\alpha-\mathrm{FeO}(\mathrm{OH})$ and hematite $\alpha-\mathrm{Fe}_{2} \mathrm{O}_{3}$. Geochim. Cosmochim. Acta 2007, 71, 1655-1673.

64. Rustad, J.R.; Wasserman, E.; Felmy, A.R. Molecular modeling of the surface charging of hematite-II. Optimal proton distribution and simulation of surface charge versus $\mathrm{pH}$ relationships. Surf. Sci. 1999, 424, 28-35.

65. Wasserman, E.; Rustad, J.R.; Felmy, A.R.; Hay, B.P.; Halley, J.W. Ewald methods for polarizable surfaces with application to hydroxylation and hydrogen bonding on the (012) and (001)surfaces of alpha- $\mathrm{Fe}_{2} \mathrm{O}_{3}$. Surf. Sci. 1997, 385, 217-239.

66. Jones, F.; Rohl, A.L.; Farrow, J.B.; Bronswijk, W.V. Molecular modeling of water adsorption on hematite. Phys. Chem. Chem. Phys. 2000, 2, 3209-3216.

67. Nguyen, M.-T.; Seriani, N.; Gebauer, R. Water adsorption and dissociation on $\alpha-\mathrm{Fe}_{2} \mathrm{O}_{3}(0001)$ : PBE+U calculations. J. Chem. Phys. 2013, 138, doi:10.1063/1.4804999.

68. Yin, S.; Ma, X.; Ellis, D.E. Initial stages of $\mathrm{H}_{2} \mathrm{O}$ adsorption and hydroxylation of Fe-terminated alpha-Fe $\mathrm{O}_{3}(0001)$ surface. Surf. Sci. 2007, 601, 2426-2437.

69. Lo, C.S.; Tanwar, K.S.; Chaka, A.M.; Trainor, T.P. Density functional theory study of the clean and hydrated hematite (1102) surfaces. Phys. Rev. B 2007, 75, 075425:1-075425:15.

70. Tanwar, K.S.; Lo, C.S.; Eng, P.J.; Catalano, J.G.; Walko, D.A.; Brown, G.E., Jr.; Waychunas, G.A.; Chaka, A.M.; Trainor, T.P. Surface diffraction study of the hydrated hematite (1102) surface. Surf. Sci. 2007, 601, 460-474.

71. Parker, S.C.; de Leeuw, N.H.; Redfern, S.E. Atomistic simulation of oxide surfaces and their reactivity with water. Faraday Discuss. 1999, 114, 381-393.

72. Lado-Touriňo, I.; Tsobnang, F. Using computational approaches to model hematite surfaces. Comput. Mater. Sci. 2000, 17, 243-248.

73. Rustad, J.R.; Felmy, A.R.; Hay, B.P. Molecular statics calculations for iron oxide and oxyhydroxide minerals: Toward a flexible model of the reactive mineral-water interface. Geochim. Cosmochim. Acta 1996, 60, 1553-1562.

74. Shroll, R.M.; Straatsma, T.P. Molecular dynamics simulations of the goethite-water interface. Mol. Simul. 2003, 29, 1-11. 
75. Rakovan, J.; Becker, U.; Hochella, M.F. Aspects of goethite surface microtopography, structure, chemistry, and reactivity. Am. Mineral. 1999, 84, 884-894.

76. Sherman, D.M.; Randall, S.R. Surface complexation of arsenie(V) to iron(III) (hydr)oxides: Structural mechanism from ab initio molecular geometries and EXAFS spectroscopy. Geochim. Cosmochim. Acta 2003, 67, 4223-4230.

77. Blanchard, M.; Morin, G.; Lazzeri, M.; Balan, E.; Dabo, I. First-principles simulation of arsenate adsorption on the (112) surface of hematite. Geochim. Cosmochim. Acta 2012, 86, 182-195.

78. Yin, S.; Ellis, D.E. DFF studies of Cr(VI) complex adsorption on hydroxylated hematite $\left(\begin{array}{lll}1 & 1 & 02\end{array}\right)$ surfaces. Surf. Sci. 2009, 603, 736-746.

79. Kwon, K.D.; Kubicki, J.D. Molecular orbital theory study on surface complex structures of phosphates to iron hydroxides: Calculation of vibrational frequencies and adsorption energies. Langmuir 2004, 20, 9249-9254.

80. Persson, P.; Nilsson, N.; Sjöberg, S. Structure and bonding of orthophosphate ions at the iron oxide aqueous interface. J. Colloid Interface Sci. 1996, 177, 263-275.

81. Arai, Y.; Sparks, D.L. ATR-FTIR spectroscopic investigation on phosphate adsorption mechanisms at the ferrihydrite-water interface. J. Colloid Interface Sci. 2001, 241, 317-326.

82. Kubicki, J.D.; Kwon, K.D.; Paul, K.W.; Sparks, D.L. Surface complex structures modelled with quantum chemical calculations: Carbonate, phosphate, sulphate, arsenate and arsenite. Eur. J. Soil Sci. 2007, 58, 932-944.

83. Acelas, N.Y.; Mejia, S.M.; Mondragón, F.; Flórez, E. Density functional theory characterization of phosphate and sulfate adsorption on Fe-(hydr)oxide: Reactivity, $\mathrm{pH}$ effect, estimation of Gibbs free energies, and topological analysis of hydrogen bonds. Comput. Theor. Chem. 2013, 1005, 16-24.

84. Grossl, P.R.; Sparks, D.L. Evaluation of contaminant ion adsorption/desorption on goethite using pressure jump relaxation kinetics. Geoderma 1995, 67, 87-101.

85. Grossl, P.R.; Eick, M.; Sparks, D.L.; Goldberg, S.; Ainsworth, C.C. Arsenate and chromate retention mechanisms on goethite. 2. Kinetic evaluation using a pressure-jump relaxation technique. Environ. Sci. Technol. 1997, 31, 321-326.

86. Catalano, J.G.; Zhang, Z.; Fenter, P.; Bedzyk, M.J. Inner-sphere adsorption geometry of Se(IV) at the hematite (100)-water interface. J. Colloid Interface Sci. 2006, 297, 665-671.

87. Mason, S.E.; Trainor, T.P.; Goffinet, C.J. DFT study of $\mathrm{Sb}(\mathrm{III})$ and $\mathrm{Sb}(\mathrm{V})$ adsorption and heterogeneous oxidation on hydrated oxide surfaces. Comput. Theor. Chem. 2012, 987, 103-114.

88. Aquino, A.J.A.; Tunega, D.; Haberhauer, G.; Gerzabek, M.H.; Lischka, H. Quantum chemical adsorption studies on the (110) surface of the mineral goethite. Phys. Chem. C 2007, 111, 877-885.

89. Han, K.N.; Healy, T.W.; Fuerstenau, D.W. The mechanism of adsorption of fatty acids and other surfactants at the oxide-water interface. J. Colloid Interface Sci. 1973, 44, 407-414.

90. Aquino, A.J.A.; Tunega, D.; Haberhauer, G.; Gerzabek, M.H.; Lischka, H. Interaction of the 2.4-dichlorophenoxyacetic acid herbicide with soil organic matter moieties: A theoretical study. Eur. J. Soil Sci. 2007, 58, 889-899.

91. San-Miguel, M.A.; Rodger, P.A. Simulation of deposition of wax to iron oxide surfaces. Mol. Simul. 2001, 26, 193-216. 
92. San-Miguel, M.A.; Rodger, P.M. Wax deposition onto $\mathrm{Fe}_{2} \mathrm{O}_{3}$ surfaces. Phys. Chem. Chem. Phys. 2003, 5, 575-581.

93. San-Miguel, M.A.; Rodger, P.M. Templates of wax deposition? Phys. Chem. Chem. Phys. 2010, 12, 3887-3894.

94. Amellal, S.; Boivin, A.; Ganier, C.P.; Schiavon, M. High sorption of phenanthrene in agricultural soils. Agron. Sustain. Dev. 2006, 26, 99-106.

95. Weigand, H.; Totsche, K.U.; Kögel-Knaber, I.; Annwiler, E.; Richnow, H.H.; Michaelis, W. Fate of anthracene in contaminated soil: Transport and biochemical transformation under unsaturated flow conditions. Eur. J. Soil Sci. 2002, 53, 71-81.

96. Weigand, H.; Totsche, K.U.; Mansfeldt, T.; Kögel-Knaber, I. Release and mobility of polycyclic aromatic hydrocarbons and iron-cyanide complexes in contaminated soil. J. Plant Nutr. Soil Sci. 2001, 164, 643-649.

97. Weigand, H.; Totche, K.U.; Huwe, B.; Kögel-Knaber, I. PAH mobility in contaminated industrial soils: A Markov chain approach to the spatial variability of soil properties and PAH levels. Geoderma 2001, 102, 371-389.

98. Laor, Y.; Farmer, W.J.; Aochi, Y.; Strom, P.F. Phenanthrene binding and sorption to dissolved and to mineral-associated humic acid. Water Res. 1998, 32, 1923-1931.

99. Ping, L.F.; Luo, Y.M.; Wu, L.H.; Qian, W.; Song, J.; Christie, P. Phenanthrene adsorption by soils treated with humic substances under different $\mathrm{pH}$ and temperature conditions. Environ. Geochem. Health 2006, 28, 189-195.

100. Rügner, H.; Kleneidam, S.; Grathwohl, P. Long term sorption kinetics of phenanthrene in aquifer materials. Environ. Sci. Technol. 1999, 33, 1645-1651.

101. Chiou, C.T.; McGroddy, S.E.; Kile, D.E. Partition characteristics of polycyclic aromatic hydrocarbons on soils and sediments. Environ. Sci. Technol. 1998, 32, 264-269.

102. Means, J.C.; Wood, S.G.; Hassett, J.J.; Banwart, W.L. Sorption of polynuclear aromatic hydrocarbons by sediments and soils. Environ. Sci. Technol. 1980, 14, 1524-1528.

103. Stauffer, T.B.; MacIntyre, W.G. Sorption of low-polarity organic compounds on oxide minerals and aquifer material. Environ. Toxicol. Chem. 1986, 5, 949-955.

104. Piatt, J.J.; Backhus, D.A.; Capel, P.D.; Eisenreich, S.J. Temperature-dependent sorption of naphthalene, phenanthrene, and pyrene to low organic carbon aquifer sediments. Environ. Sci. Technol. 1996, 30, 751-760.

105. Xia, G.; Ball, W.P. Adsorption-partitioning uptake of nine low-polarity organic chemicals on a natural sorbent. Environ. Sci. Technol. 1999, 33, 262-269.

106. Allen-King, R.M.; Grathwohl, P.; Ball, W.P. New modeling paradigms for the sorption of hydrophobic organic chemicals to heterogeneous carbonaceous matter in soils, sediments, and rocks. Adv. Water Res. 2002, 25, 985-1016.

107. Mader, B.T.; Goss, K.U.; Eisenreich, S.J. Sorption of nonionic, hydrophobic organic chemicals to mineral surfaces. Environ. Sci. Technol. 1997, 31, 1079-1086.

108. Ma, J.C.; Dougherty, D.A. The cation- $\pi$ interaction. Chem. Rev. 1997, 97, 1303-1324.

109. Zaric, S.D. Metal ligand aromatic cation- $\pi$ interactions. Eur. J. Inorg. Chem. 2003, 12, 2197-2209. 
110. Zhu, D.; Herbert, B.E.; Schlautman, M.A.; Carraway, E.R.; Hur, J. Cation- $\pi$ bonding: A new perspective on the sorption of polycyclic aromatic hydrocarbons to mineral surfaces. J. Environ. Qual. 2004, 33, 1322-1330.

111. Kresse, G.; Furthmuller, J. Efficiency of ab-initio total energy calculations for metals and semiconductors using a plane-wave basis set. Comput. Mater. Sci. 1996, 6, 15-50.

112. Kresse, G.; Furthmuller, J. Efficient iterative schemes for ab initio total-energy calculations using a plane-wave basis set. Phys. Rev. B 1996, 54, 11169-11186.

113. Kresse, G.; Hafner, J. Ab initio molecular dynamics for open-shell transition metals. Phys. Rev. $B$ 1993, 48, 13115-13118.

114. Kresse, G.; Hafner, J. Norm-conserving and ultrasoft pseudopotentials for first-row and transition elements. J. Phys. Condens. Matter 1994, 6, 8245-8257.

115. Perdew, J.P.; Zunger, A. Self-interaction correction to density-functional approximations for many-electron systems. Phys. Rev. B 1981, 23, 5048-5079.

116. Perdew, J.P.; Chevary, J.A.; Vosko, S.H.; Jackson, K.A.; Pederson, M.R.; Singh, D.J.; Fiolhais, C. Atoms, molecules, solids, and surfaces: Applications of the generalized gradient approximation for exchange and correlation. Phys. Rev. B 1992, 46, 6671-6687.

117. Dudarev, S.L.; Liechtenstein, A.I.; Castell, M.R.; Briggs, G.A.D.; Sutton, A.P. Surface states on $\mathrm{NiO}(100)$ and the origin of the contrast reversal in atomically resolved scanning tunneling microscope images. Phys. Rev. B 1997, 56, 4900-4908.

118. Dudarev, S.L.; Botton, G.A.; Savrasov, S.Y.; Humphreys, C.J.; Sutton, A.P. Electron-energy-loss spectra and the structural stability of nickel oxide: An LSDA+U study. Phys. Rev. B 1998, 57, 1505-1509.

119. Rohrbach, A.; Hafner, J.; Kresse, G. Electronic correlation effects in transition-metal sulfides. J. Phys. Condens. Matter 2003, 15, 979-996.

120. Grimme, S. Semiempirical GGA-type density functional constructed with a long-range dispersion correction. J. Comput. Chem. 2006, 27, 1787-1799.

121. Dzade, N.Y.; Roldan, A.; de Leeuw, N.H. Adsorption of methylamine on mackinawite (FeS) surfaces: A density functional theory study. J. Chem. Phys. 2013, 139, doi:10.1063/1.4822040.

122. Irrera, S.; Roldan, A.; Portalone, G.; de Leeuw, N.H. The role of hydrogen bonding and proton transfer in the formation of uracil networks on the gold (100) surface: A density functional theory approach. J. Phys. Chem. C 2013, 117, 3949-3957.

123. Monkhorst, H.J.; Pack, J.D. Special points for Brillouin-zone integrations. Phys. Rev. B 1976, 13, 5188-5192.

124. Rohr, F.; Baumer, M.; Freund, H.J.; Mejias, J.A.; Staemmler, V.; Muller, S.; Hammer, L.; Heinz, K. Strong relaxations at the $\mathrm{Cr}_{2} \mathrm{O}_{3}(0001)$ surface as determined via low-energy electron diffraction and molecular dynamics simulations. Surf. Sci. 1997, 372, L291-L297.

125. Mackrodt, W.C.; Davey, R.J.; Black, S.N.; Docherty, R. The morphology of $\alpha-\mathrm{Al}_{2} \mathrm{O}_{3}$ and $\alpha-\mathrm{Fe}_{2} \mathrm{O}_{3}$ : The importance of surface relaxation. J. Cryst. Growth 1987, 80, 441-446.

126. Ching, W.Y.; Xu, Y.-N. First-principles calculation of electronic, optical, and structural properties of $\alpha-\mathrm{Al}_{2} \mathrm{O}_{3}$.J. Am. Ceram. Soc. 1994, 77, 404-411.

127. Freier, S.; Greenshpan, P.; Hillman, P.; Shechter, H. The antiferromagnetic curie point in $\alpha-\mathrm{Fe}_{2} \mathrm{O}_{3}$. Phys. Lett. 1962, 2, 191-192. 
128. Lielmezs, J.; Chaklader, A.C.D. Reversible thermal effect in $\alpha-\mathrm{Fe}_{2} \mathrm{O}_{3}$ at $690 \pm 5{ }^{\circ} \mathrm{C} . J$. Appl. Phys. 1965, 36, 866-867.

129. Punkkinen, M.P.J.; Kokko, K.; Hergert, W.; Väyrynen, I.J. $\mathrm{Fe}_{2} \mathrm{O}_{3}$ within the LSDA+U approach. J. Phys. Condens. Matter 1999, 11, 2341-2349.

130. Sandratskii, L.M.; Uhl, M.; Kübler, J. Band theory for electronic and magnetic properties of $\alpha-\mathrm{Fe}_{2} \mathrm{O}_{3}$. J. Phys. Condens. Matter 1996, 8, 983-989.

131. Uozumi, T.; Okada, K.; Kotani, A. Theory of photoemission spectra for $\mathrm{M}_{2} \mathrm{O}_{3}(\mathrm{M}=\mathrm{Ti}, \mathrm{V}, \mathrm{Cr}$, $\mathrm{Mn}, \mathrm{Fe}$ ) compounds. J. Electron. Spectrosc. Relat. Phenom. 1996, 78, $103-106$.

132. Fujimori, A.; Saeki, M.; Kimizuka, N.; Taniguchi, M.; Suga, M. Photoemission satellites and electronic structure of $\mathrm{Fe}_{2} \mathrm{O}_{3}$. Phys. Rev. B 1989, 34, 7318-7333.

133. Ciccacci, F.; Braicovich, L.; Puppin, E.; Vescovo, E. Empty electron states in $\mathrm{Fe}_{2} \mathrm{O}_{3}$ by ultraviolet inverse-photoemission spectroscopy. Phys. Rev. B 1991, 44, 10444-10448.

134. Sivula, K.; Le Formal, F.; Grätzel, M. Solar water splitting: Progress using hematite $\left(\alpha-\mathrm{Fe}_{2} \mathrm{O}_{3}\right)$ photoelectrodes. ChemSusChem 2011, 4, 432-439.

135. Coey, J.; Sawatzky, G. A study of hyperfine interactions in the system $\left(\mathrm{Fe}_{1-x} \mathrm{Rh}_{x}\right)_{2} \mathrm{O}_{3}$ using the Mossbauer effect (Bonding parameters). J. Phys. C 1971, 4, 2386-2407.

136. Kren, E.; Szabo, P.; Konczos, G. Neutron diffraction studies on the $(1-x) \mathrm{Fe}_{2} \mathrm{O}_{3}-x \mathrm{Rh}_{2} \mathrm{O}_{3}$ system. Phys. Lett. 1965, 19, 103-104.

137. Kiejna, A.; Pabisiak, T. Surface properties of clean and Au or Pd covered hematite $\left(\alpha-\mathrm{Fe}_{2} \mathrm{O}_{3}\right)(0001)$. J. Phys. Condens. Matter 2012, 24, 095003:1-095003:16.

138. Liao, P.; Carter, E.A. Testing variations of the GW approximation on strongly correlated transition metal oxides: Hematite $\left(\alpha-\mathrm{Fe}_{2} \mathrm{O}_{3}\right)$ as a benchmark. Phys. Chem. Chem. Phys. 2011, 13, 15189-15199.

139. Barteau, M.A. Site requirements of reactions on oxide surfaces. J. Vac. Technol. A 1993, 11, 2162-2168.

140. Kurtz, R.; Henrich, V.E. Geometric structure of the $\alpha-\mathrm{Fe}_{2} \mathrm{O}_{3}(001)$ surface: A LEED and XPS study. Surf. Sci. 1983, 129, 345-354.

141. Lad, R.J.; Henrich, V.E. Structure of $\alpha-\mathrm{Fe}_{2} \mathrm{O}_{3}$ single crystal surfaces following $\mathrm{Ar}^{+}$ion bombardment and annealing in $\mathrm{O}_{2}$. Surf. Sci. 1988, 193, 81-93.

142. Ritter, M.; Weiss, W. $\mathrm{Fe}_{3} \mathrm{O}_{4}(111)$ surface structure determined by LEED crystallography. Surf. Sci. 1999, 432, 81-94.

143. Ketteler, G.; Weiss, W.; Ranke, W. Surface structures of $\alpha-\mathrm{Fe}_{2} \mathrm{O}_{3}(0001)$ phases determined by LEED crystallography. Surf. Rev. Lett. 2001, 8, 661-683.

144. Lübbe, M.; Moritz, W. A LEED analysis of the clean surfaces of $\alpha-\mathrm{Fe}_{2} \mathrm{O}_{3}(0001)$ and $\alpha-\mathrm{Cr}_{2} \mathrm{O}_{3}(0001)$ bulk single crystals. J. Phys. Condens. Matter 2009, 21, 134010:1-134010:9.

145. Eggleston, C.M.; Hochella, M.F. The structure of hematite $\{001\}$ surfaces by scanning tunneling microscopy: Image interpretation, surface relaxation, and step structure. Am. Mineral. 1992, 77, 911-922.

146. Condon, N.G.; Murray, P.W.; Leibsle, F.M.; Thornton, G.; Lennie, A.R.; Vaughan, D.J. $\mathrm{Fe}_{3} \mathrm{O}_{4}(111)$ termination of $\alpha-\mathrm{Fe}_{2} \mathrm{O}_{3}(0001)$. Surf. Sci. 1994, 310, L609-L613.

147. Condon, N.G.; Leibsle, F.M.; Lennie, A.R.; Murray, P.W.; Vaughan, D.J.; Thornton, G. Biphase ordering of iron oxide surfaces. Phys. Rev. Lett. 1995, 75, 1961-1964. 
148. Condon, N.G.; Leibsle, F.M.; Lennie, A.R.; Murray, P.W.; Parker, T.M.; Vaughan, D.J.; Thornton, G. Scanning tunnelling microscopy studies of $\alpha-\mathrm{Fe}_{2} \mathrm{O}_{3}(0001)$. Surf. Sci. 1998, 397, $278-287$.

149. Shaikhutdinov, S.K.; Weiss, W. Oxygen pressure dependence of the $\alpha-\mathrm{Fe}_{2} \mathrm{O}_{3}(0001)$ surface structure. Surf. Sci. 1999, 432, L627-L634.

150. Chambers, S.A.; Yi, S.I. Fe termination for $\alpha-\mathrm{Fe}_{2} \mathrm{O}_{3}(0001)$ as grown by oxygen-plasma-assisted molecular beam epitaxy. Surf. Sci. 1999, 439, L785-L791.

151. Thevuthasan, S.; Kim, Y.J.; Yi, S.I.; Chambers, S.A.; Morais, J.; Denecke, R.; Fadley, C.S.; Liu, P.; Kendelewica, T.; Brown, G.E., Jr. Surface structure of MBE-grown $\alpha$-Fe2O3(0001) by intermediate-energy X-ray photoelectron diffraction. Surf. Sci. 1999, 425, 276-286.

152. Greene, M.E.; Chiaramonti, A.N.; Christensen, S.T.; Cao, L.; Bedzyk, M.J.; Hersam, M.C. Controlled nanoscale morphology of hematite (0001) surfaces grown by chemical vapor transport. Adv. Mater. 2005, 17, 1765-1768.

153. Mackrodt, W.C. Atomistic simulation of oxide surfaces. Phys. Chem. Miner. 1988, 15, 228-237.

154. Reeves, N.J.; Mann, S. Influence of inorganic and organic additives on the tailored synthesis of iron oxides. J. Chem. Soc. Faraday Trans. 1991, 87, 3875-3880.

155. Jin, J.; Ma, X.; Kim, C.-Y.; Ellis, D.E.; Bedzyk, M.J. Adsorption of V on a hematite (0001) surface and its oxidation: Submonolayer coverage. Surf. Sci. 2007, 601, 3082-3098.

156. Henderson, M.A. Insights into the $(1 \times 1)$-to- $(2 \times 1)$ phase transition of the $\alpha-\mathrm{Fe}_{2} \mathrm{O}_{3}(012)$ surface using EELS, LEED and water TPD. Surf. Sci. 2002, 515, 253-262.

157. Henderson, M.A.; Joyce, S.A.; Rustad, J.R. Interaction of water with the $(1 \times 1)$ and $(2 \times 1)$ surfaces of $\alpha-\mathrm{Fe}_{2} \mathrm{O}_{3}$ (012). Surf. Sci. 1998, 417, 66-81.

158. Chatman, S.; Zarzyckib, P.; Rosso, K.M. Surface potentials of (001), (012), (113) hematite $\left(\alpha-\mathrm{Fe}_{2} \mathrm{O}_{3}\right)$ crystal faces in aqueous solution. Phys. Chem. Chem. Phys. 2013, 15, 13911-13921.

159. Lide, D.R. CRC Handbook of Chemistry and Physics, 91st ed.; CRC Press: Boca Raton, FL, USA, 2010.

160. Bader, R.F.W. Atoms in Molecules-A Quantum Theory; Oxford University Press: New York, NY, USA, 1990.

161. Knickelbein, M.B. Nickel clusters: The influence of adsorbates on magnetic moments. J. Chem. Phys. 2002, 116, 9703-9711.

162. Błoński, P.; Kiejna, A.; Hafner, J. Theoretical study of oxygen adsorption at the $\mathrm{Fe}(110)$ and (100) surfaces. Surf. Sci. 2005, 590, 88-100.

(C) 2014 by the authors; licensee MDPI, Basel, Switzerland. This article is an open access article distributed under the terms and conditions of the Creative Commons Attribution license (http://creativecommons.org/licenses/by/3.0/). 